\title{
Flora da Bahia: Poaceae - Dichanthelium (Panicoideae)
}

\author{
Andreza Oliveira Matos ${ }^{1^{*}}$, Christian da Silva ${ }^{2, \mathrm{~b}}$ \& Reyjane Patrícia de Oliveira ${ }^{1, \mathrm{c}}$ \\ ${ }^{1}$ Programa de Pós-graduação em Botânica, Departamento de Ciências Biológicas, Universidade Estadual de Feira \\ de Santana, Feira de Santana, Bahia, Brasil. \\ ${ }^{2}$ Universidade do Estado de Santa Catarina, Departamento de Engenharia de Pesca e Ciências Biológicas, Centro \\ de Educação Superior da Região Sul, Laguna, Santa Catarina, Brasil.
}

\begin{abstract}
Resumo - Aqui, apresentamos a flora do gênero Dichanthelium (Panicoideae, Poaceae) para o estado da Bahia, Brasil. São reconhecidas 13 espécies, das quais oito são endêmicas. O presente trabalho inclui chave de identificação para as espécies, descrições, ilustrações, mapas de distribuição e comentários sobre os táxons.
\end{abstract}

Palavras-chave adicionais: florística, gramíneas, Paniceae, taxonomia.

\begin{abstract}
Flora of Bahia: Poaceae - Dichanthelium) - The flora of the genus Dichanthelium (Panicoideae, Poaceae) for the state of Bahia, Brazil, is herein presented. We recognize 13 species, from which eight are endemic. This work includes an identification key to the species, descriptions, illustrations, distribution maps, and notes on the taxa.
\end{abstract}

Additional keywords: floristics, grasses, Paniceae, taxonomy.

Poaceae pertence ao grupo das monocotiledôneas (APG IV 2016) e compreende cerca de 768 gêneros e 11.500 espécies (Soreng et al. 2017), apresentando distribuição cosmopolita (Longhi-Wagner et al. 2001; Kellogg 2015). Suas espécies cobrem amplas áreas de vegetação campestre e florestal (Longhi-Wagner 2012; Kellogg 2015; Soreng et al. 2017), estando presentes em todos os biomas brasileiros, em diversos tipos de formação vegetal e condições climáticas (BFG 2015). Atualmente, encontra-se dividida em 12 subfamílias, das quais apenas Puelioideae não ocorre no Brasil (Longhi-Wagner 2012; Soreng et al. 2017). Está entre as dez famílias mais diversas no Brasil, apresentando 232 gêneros e cerca de 1.500 espécies, das quais cerca de 500 são endêmicas (Flora do Brasil 2020). Na Bahia, ocorrem 133 gêneros e aproximadamente 550 espécies (Flora do Brasil 2020), dentre eles Dichanthelium (Hitchc. \& Chase) Gould, que pode ser caracterizado pela presença de dimorfismo foliar (exclusivo das espécies norte-americanas), inflorescências paniculadas e espiguetas dorsiventralmente comprimidas, obovoides a elipsoides, com gluma superior e lema inferior (5-)7-11(-15)-nervados e antécio superior curtamente apiculado (Aliscioni et al. 2003; Kellogg 2015).

Dichanthelium (Hitchc. \& Chase) Gould

Ervas perenes ou anuais, sem rizomas ou com rizomas curtos, formando ou não uma roseta basal de folhas amplas durante o inverno (nas espécies norte americanas). Colmos eretos ou decumbentes,

\footnotetext{
*Autora para correspondência: aandreza.oliveiram@gmail.com;

a christian.silva@udesc.br; b rpatricia@uefs.br

Editor responsável: Alessandro Rapini

Submetido: 23 set. 2021; aceito: 6 dez. 2021

Publicação eletrônica: 22 dez. 2021; versão final: 22 dez. 2021
}

livremente ramificados nos nós superiores; entrenós ocos, com ou sem glândulas. Bainhas foliares estriadas, glabras a densamente pilosas, com ou sem glândulas, margens pilosas ou glabras; lígula membranoso-ciliada; colo glabro ou piloso. Lâminas lineares a oval-lanceoladas, planas ou involutas, glabras a densamente pilosas; dimorfismo foliar presente ou não. Panículas terminais e/ou axilares, laxas, abertas, ocasionalmente contraídas, ramificações com ou sem glândulas, ráquis glabra ou pilosa. Espiguetas geralmente elipsoides ou obovoides, glabras a pilosas, esverdeadas, às vezes arroxeadas, com dois antécios; gluma inferior reduzida $(1 / 4-1 / 3$ do comprimento da espigueta) a desenvolvida (até $3 / 4$ do comprimento da espigueta), (0)1-7-nervada, aguda ou truncada; entrenó entre as glumas conspícuo ou inconspícuo; gluma superior geralmente não cobrindo o ápice do antécio superior, (5)7-11(-15)-nervada, aguda ou obtusa; antécio inferior neutro ou com flor masculina; lema inferior glumiforme, (5)7-11(-15)nervado; pálea inferior conspícua, mais curta ou tão longa quanto o lema, geralmente hialina; antécio superior com flor bissexuada, endurecido, brilhante ou não, com papilas conspícuas ou inconspícuas ao longo de toda a superfície, piloso a glabro, apiculado, com ou sem tricomas no apículo, geralmente esbranquiçado a castanho-escuro ou preto, podendo ser preto ou marrom na maturidade; lodículas 2 , truncadas; estames 3; estigmas 2, plumosos. Cariopses obvoides ou elipsoides; hilo punctiforme, oblongo ou obovado; embrião $1 / 3$ ou menor que o comprimento da cariopse.

Dichanthelium foi descrito como um subgênero de Panicum L. por Hitchcook \& Chase (1910), sendo elevado ao nível genérico por Gould (1974). Entretanto, muitos autores continuaram a considerá-lo dentro da circunscrição de Panicum por muitos anos, principalmente devido a similaridades tanto em 
caracteres vegetativos quanto reprodutivos, tais como: panículas abertas a laxas, espiguetas dorsiventralmente comprimidas e antécio superior endurecido (Lelong 1984; Clayton \& Renvoize 1986; Zuloaga 1987; Zuloaga \& Morrone 1991a; Zuloaga et al. 1993). No entanto, Dichanthelium difere de Panicum pela presença de um curto apículo no antécio superior, dimorfismo foliar e fotossíntese do tipo $\mathrm{C}_{3}$ (vs. antécio superior mútico, dimorfismo foliar ausente e fotossíntese $\mathrm{C}_{4}$ do subtipo NAD-me em Panicum).

Com a realização de estudos moleculares, Dichanthelium tem sido recuperado como um gênero monofilético (Giussani et al. 2001; Aliscioni et al. 2003; Morrone et al. 2008, 2012; Zuloaga et al. 2014).
Encontra-se incluído na subfamília Panicoideae, tribo Paniceae (Morrone et al. 2012), e, mais recentemente, foi posicionado na subtribo Dichantheliinae, juntamente com o gênero Adenochloa Zuloaga, restrito à África (Zuloaga et al. 2014). É amplamente distribuído, desde o Canadá até a Argentina e Brasil (Brown \& Smith 1975), podendo ser encontrado em bordas de florestas úmidas e em áreas abertas, em solos arenosos secos ou úmidos, do nível do mar a $3.000 \mathrm{~m}$ de altitude (Aliscioni et al. 2003). O número de espécies no gênero varia entre 55 (Aliscioni et al. 2003) e 120 espécies (Zuloaga et al. 2014), das quais 25 são confirmadas no Brasil e 13 ocorrem na Bahia (Delfini et al. 2020; Matos et al. 2020) (Figuras 1-7).

\section{Chave para as espécies}

1. Lâminas foliares amplexicaules, base cordada.

2. Panículas paucifloras, incluídas em meio às folhas terminais ou parcialmente exsertas .. 8. D. cumbucanum

2'. Panículas multifloras, exsertas.

3. Antécio superior inflado na base; hilo obovado 3. D. arenicola

3'. Antécio superior não inflado na base; hilo punctiforme.

4. Antécio superior 1-1,6 mm compr.; cariopses 1-1,2 mm compr.

5. Gluma superior e lema inferior 7- ou 9-nervados; cariopses elipsoides

5'. Gluma superior e lema inferior 5-nervados; cariopses obovoides

12. D. sciurotoides

4'. Antécio superior 1,5-2,1 mm compr.; cariopses ca. 1,5 mm compr.

6. Gluma inferior até $1 / 2$ do comprimento da espigueta 11. D. sciurotis

6'. Gluma inferior $1 / 2-3 / 4$ do comprimento da espigueta

1'. Lâminas foliares não amplexicaules, base atenuada a subcordada (cordada a subcordada em D. aequivaginatum). 7. Gluma inferior $3 / 4-4 / 5$ do comprimento da espigueta.

8. Panículas pilosas; gluma inferior dimórfica 1-, 3- ou 7-nervada 9. D. hebotes

8'. Panículas glabras; gluma inferior monomórfica, 3-nervada

4. D. assurgens

7'. Gluma inferior $1 / 4-1 / 2$ do comprimento da espigueta.

9. Plantas com glândulas nas bainhas, lâminas e ramos das panículas

1. D. adenorhachis

9'. Plantas sem glândulas nas bainhas e lâminas, raramente presentes nos ramos das panículas.

10. Lâminas foliares glabras, margens planas

2. D. aequivaginatum

10’. Lâminas foliares esparsamente pilosas a pilosas; margens involutas.

11. Lâminas foliares oval-lanceoladas; espiguetas glabras a esparsamente pilosas

5. D. barbadense

11'. Lâminas foliares linear-lanceoladas; espiguetas densamente pilosas.

12. Gluma inferior $1 / 2$ do comprimento da espigueta; cariopses obovoides

6. D. cabrerae

12'. Gluma inferior $3 / 4$ ou maior que o comprimento da espigueta; cariopses elipsoides

1. Dichanthelium adenorhachis (Zuloaga \& Morrone) Zuloaga, Am. J. Bot. 90: 816. 2003.

Figuras 3A, B e 4; Zuloaga \& Morrone (1991a: fig. 2).

Planta perene. Colmos até $1 \mathrm{~m}$ compr., decumbentes; nós glabros ou pilosos; entrenós 1,5-4,5 cm compr., glabros. Bainhas foliares 2,5-4 cm compr., glabras, com glândulas, caducas, uma margem pilosa e outra glabra, ou ambas pilosas; lígula $0,2-0,6 \mathrm{~mm}$ compr.; colo glabro a piloso. Lâminas 4-7,5 cm × 3-6 $\mathrm{mm}$, lanceoladas, não congestas no colmo, face adaxial escabra, face abaxial glabra, com glândulas, base subcordada, não amplexicaule, ápice agudo, margens longo-ciliadas próximo à base, com tricomas tuberculosos, ou escabras, planas. Panículas 4,5-7 × 4 $5 \mathrm{~cm}$, ramificadas, exsertas, paucifloras; ráquis glabra, com glândulas; ramos de primeira ordem pilosos, com glândulas; pulvino piloso; pedicelo piloso. Espiguetas 2,7-3,1 × 0,9-1,2 mm, elipsoides, estramíneas, curtopilosas; gluma inferior $0,7-0,8 \mathrm{~mm}$ compr., menor que $1 / 3$ do comprimento da espigueta, monomórfica, enérvea ou 1-nervada, curto-pilosa; gluma superior 2,7-2,9 $\times$ 0,8-1,3 mm, 9-nervada, curto-pilosa; lema inferior 2,62,9 × 1-1,4 mm, 9-nervado, curto-piloso; pálea inferior ca. 1,8 $\times 0,4 \mathrm{~mm}$, lanceolada, hialina, ciliada nas margens; flor inferior ausente; antécio superior 2-2,3 $\times$ ca. $0,8 \mathrm{~mm}$, elipsoide, não inflado na base, amarelado quando jovem, amarronzado na maturidade, glabro com microtricomas no ápice do lema. Cariopses $1-1,7 \times$ 0,5-0,7 mm, elipsoides, marrons; hilo punctiforme.

Dichanthelium adenorhachis é endêmica da Bahia, conhecida até o momento apenas do Pico das Almas, na Chapada Diamantina, ocorrendo entre 1.000 e $1.850 \mathrm{~m}$ 
de altitude (Zuloaga \& Morrone 1991a; Zuloaga et al. 1993). F6: campos rupestres, em solos pedregosos e úmidos.

Material selecionado - Rio de Contas, $13^{\circ} 32^{\prime} \mathrm{S}, 42^{\circ} 53^{\prime} \mathrm{W}, 21$ jul. 1979, S.A. Mori et al. 12451 (holótipo CEPEC).

Assemelha-se a Dichanthelium stipiflorum, podendo ser distinguida pelas lâminas foliares lanceoladas com base atenuada (vs. lâminas oval-lanceoladas, cordadas e amplexicaules em $D$. stipiflorum), espiguetas de 2,7-3,1 mm compr., com entrenó inconspícuo entre as glumas (vs. espiguetas de 2-2,6 $\mathrm{mm}$ compr., com entrenó conspícuo entre as glumas), gluma inferior enérvea ou 1-nervada (vs. gluma inferior 3- ou 5-nervada).

É a única espécie de Dichanthelium descrita para a Bahia que apresenta glândulas no corpo da planta e nas panículas, caraterística compartilhada com apenas quatro outras espécies congenéricas e registradas até o momento apenas no sudeste e sul do país: $D$. sabulorum (Lam.) Gould \& C.A.Clark, D. sphaerocarpon (Elliot) Gould, D. stigmosum (Trin.) Zuloaga e D. strigosum (Muhl. ex Elliot) Freckman (Zuloaga et al. 1993).

2. Dichanthelium aequivaginatum (Swallen) Zuloaga, Am. J. Bot. 90: 816. 2003.

= Panicum appressifolium Swallen, Mem. New York Bot. Gard. 9: 258. 1957.

= Panicum belmonte Renvoize, Kew Bull. 37: 325. 1982.

= Panicum thinophilum Renvoize, Kew Bull. 39: 180. 1984.

Figuras 3C, D e 4.

Planta provavelmente anual. Colmos $0,5-1,5 \mathrm{~m}$ compr., eretos; nós pilosos; entrenós 2-9 cm compr., glabros ou pilosos. Bainhas foliares $4-8 \mathrm{~cm}$ compr., glabras, sem glândulas, persistentes, ambas as margens pilosas; lígula $0,3-0,6 \mathrm{~mm}$ compr.; colo piloso. Lâminas 3,3-12 × 0,4-1,5 cm, linear-lanceoladas, não congestas no colmo, glabras em ambas as faces, sem glândulas, base cordada a subcordada, não amplexicaule, ápice agudo, margens escabras e ciliadas, planas. Panículas $1-12 \times 4-7 \mathrm{~cm}$, ramificadas, exsertas, multifloras; ráquis glabra, sem glândulas; ramos de primeira ordem glabros, sem glândulas; pulvino curtopiloso ou glabro; pedicelo glabro. Espiguetas 2-2,6 $\times$ 0,7-1 mm, ovais, elipsoides ou elíptico-oblongas, verdes, às vezes arroxeadas na base, glabras; gluma inferior $1-1,4 \mathrm{~mm}$ compr., $1 / 2$ do ou menor que $\mathrm{o}$ comprimento da espigueta, monomórfica, 1- ou 3nervada, glabra; gluma superior 1,6-1,8 × 0,8-1 mm, 7ou 9-nervada, glabra; lema inferior 1,5-1,7 $\times 0,9-1,1$ $\mathrm{mm}, 7$ - ou 9-nervado, glabro; pálea inferior $1-1,2 \times$ ca. $0,3 \mathrm{~mm}$, linear-lanceolada, hialina, glabra; flor inferior ausente; antécio superior 1,7-2 × 0,6-0,8 mm, elipsoide, não inflado na base, estramíneo, glabro. Cariopses 0,9 1,4 $\times$ ca. 0,5 mm, elipsoides, marrons; hilo punctiforme.

Ocorre na Venezuela, nos estados Bolivar e Amazonas, Guiana e Brasil, entre 900 e $2.000 \mathrm{~m}$ de altitude (Zuloaga et al. 1993). Na Venezuela, é frequente em savanas ou planícies de montanhas, em solos arenosos (Zuloaga et al. 1993). No Brasil, tem sido registrada para a Bahia, Rio de Janeiro e Santa Catarina, crescendo em ambientes de Cerrado e Mata Atlântica (Delfini et al. 2020). F5, F6, G5, H6, H7, H8, H9 e I5: campos rupestres e restingas, em solos arenosos e pedregosos.

Material selecionado - Amargosa, $14^{\circ} 09^{\prime} \mathrm{S}, 39^{\circ} 49^{\prime} \mathrm{W}, 19$ out. 2007, J.L. Paixão et al. 1374 (HUEFS); Belmonte, 1600'S, $39^{\circ} 03^{\prime}$ W, 24 mar. 1974, R.M. Harley 17383 (CEPEC); Canavieiras, 12 out. 1998, S.C. Sant'Ana et al. 719 (HUEFS); Igrapiúna, 1349'S, 3907’W, 29 jul. 2008, K.M. Pimenta et al. 130 (HUEFS); Ilhéus, 15 mar. 1943, R.L. Fróes 19950 (holótipo US [foto]); Lençóis, 12²7'S, 41ํㄷ' 'W, 22 set. 1994, A.M. Giullietti 877 (ALCB, HUEFS); Maraú, $14^{\circ} 42^{\prime}$ S, 3900'W, 24 jul. 2001, L.A. Mattos-Silva et al. 4344 (HUEFS); Mucugê, 15 mar. 2006, C.F. Azevêdo-Gonçalves 65 (HUEFS); Palmeiras, $12^{\circ} 34^{\prime} \mathrm{S}, 4^{\circ} 23^{\prime} \mathrm{W}, 22$ ago. 2009, J.C. Brito 135 (HUEFS); Ruy Barbosa, $12^{\circ} 18^{\prime}$ 'S, $40^{\circ} 28^{\prime}$ 'W, 16 out. 1978, E.F. Almeida 22 (HUEFS); Salvador, 1258'S, 38²2'W, 9 abr. 1980, T. Plowman et al. 10045 (RB).

Material adicional examinado - BRASIL. RIO DE JANEIRO: Rio de Janeiro, 16 jun. 1969, Sucre et al. 5349 (HUEFS). GUIANA. KAMARANG RIVER: Wenamu Trail, British Guiana, 10 nov. 1951, M. Maguire \& D.F. Fanshawe 32564 (US [foto]).

Segundo Zuloaga et al. (1993), Dichanthelium aequivaginatum inclui em sua sinonímia Panicum appressifolium, P. thinophylum e P. belmonte, a primeira descrita como endêmica das Guianas e as outras duas inicialmente consideradas endêmicas da Bahia (Maguire \& Wardack 1957; Renvoize 1982, 1984). No entanto, a análise dos materiais citados por Zuloaga et al. (1993), amostras coletadas na Bahia, materiais-tipo e protólogos associados a esses nomes demonstrou variações morfológicas consideráveis, sugerindo que $D$. aequivaginatum represente um complexo, potencialmente com duas ou três espécies, tendo ainda várias semelhanças morfológicas com $D$. assurgens e $D$. hebotes, conforme comentários dessas duas espécies a seguir.

O tipo de Panicum thinophilum foi coletado em uma área de restinga, em Salvador (Renvoize 1982); de acordo com sua descrição, possui inflorescência pouco exserta nas folhas superiores, colmo ramificado e folhas densamente congestas (Renvoize 1982; Zuloaga et al. 1993), contrastando com as panículas exsertas ou longoexsertas (Swallen 1949; Maguire \& Wardack 1957; Renvoize 1982), colmos não ramificados e folhas não congestas de D. aequivaginatum (Zuloaga et al. 1993). Quanto às espiguetas, a descrição original de $P$. aequivaginatum indica gluma inferior 3-nervada e gluma superior e lema inferior 9-nervados, sem informação sobre pilosidade (Swallen 1949). Para $P$. appressifolium, a descrição original indica gluma inferior 1-nervada, raramente com nervuras laterais, gluma superior e lema inferior 7-nervados, glabros (Maguire \& Wardack 1957). Já no protólogo de $P$. belmonte, são citadas espiguetas elíptico-oblongas, glabras, com gluma inferior 1-nervada e gluma superior 7-nervada (Renvoize 1982), enquanto para $P$. thinophilum são citadas espiguetas ovais, glabras, com 
gluma inferior $1 / 2$ comprimento da espigueta, 1 -nervada, e gluma superior 7-nervada (Renvoize 1984).

Quando Zuloaga et al. (1993) trataram toda essa variação sob $D$. aequivaginatum, eles caracterizaram a espécie como tendo "espiguetas elipsoides, glabras, com gluma inferior 3-nervada, gluma superior e lema inferior 9-nervados", desconsiderando a variação nas amostras examinadas. No presente trabalho, adotamos a circunscrição ampla proposta por Zuloaga et al. (1993), especialmente pela impossibilidade de recoletar amostras suficientes para abarcar essa variação morfológica, mas ressaltamos a necessidade de estudos mais detalhados para a delimitação dessa espécie.

3. Dichanthelium arenicola A.O.Matos \& R.P.Oliveira, Phytotaxa 447(3): 156. 2020.

Figuras 1A, B, 2A, 3E, F e 4; Matos et al. (2020: fig. 5).

Planta perene. Colmos $0,1-1 \mathrm{~m}$ compr., decumbentes; nós glabros a esparsamente pilosos; entrenós 0,5-7 cm compr., pubérulos. Bainhas foliares 1,2-3,5 cm compr., pilosas, principalmente na base, sem glândulas, persistentes, uma margem pilosa, a outra glabra; lígula ca. $0,4 \mathrm{~mm}$ compr.; colo piloso. Lâminas $1-2,5 \times 0,5-1 \mathrm{~cm}$, oval-lanceoladas a lanceoladas, não congestas no colmo, pilosas em ambas as faces, sem glândulas, base cordada, amplexicaule, ápice agudo, margens ciliadas, planas. Panículas $1,5-5 \times 0,5-6 \mathrm{~cm}$, ramificadas, exsertas, multifloras; ráquis pilosa, sem glândulas; ramos de primeira ordem pilosos, sem glândulas; pulvino piloso; pedicelo esparsamente piloso. Espiguetas 1,9-2,1 × 0,7-0,8 mm, elipsoides, verdes com manchas arroxeadas, pilosas; gluma inferior $1-1,2 \times$ ca. $0,5 \mathrm{~mm}, 1 / 2$ do comprimento da espigueta, monomórfica, 1- ou 3-nervada, pilosa; gluma superior 1,6-1,7 × 1-1,1 mm, 9-nervada, pilosa; lema inferior ca. 1,8 × 1,2 mm, 9-nervado, piloso; pálea inferior 1,1-1,3 $\times$ ca. $0,3 \mathrm{~mm}$, lanceolada, hialina, glabra; flor inferior ausente; antécio superior 1,6-1,9 × 0,5-0,7 mm, elipsoide, inflado na base, estramíneo, às vezes arroxeado em direção ao apículo, glabro com tricomas no ápice do lema. Cariopses ca. 0,9 $\times 0,4 \mathrm{~mm}$, obovoides, marrons; hilo obovado.

Endêmica da Bahia, conhecida apenas do Tabuleiro do Tigre, Morro do Chapéu, na porção norte da Chapada Diamantina, ocorrendo a cerca de $1.000 \mathrm{~m}$ de altitude (Matos et al. 2020). F4: areais, próximo a áreas de solos pedregosos.

Material selecionado - Morro do Chapéu, $11^{\circ} 35^{\text {' }} \mathrm{S}, 41^{\circ} 09^{\prime} \mathrm{W}$, 8 nov. 2018, A.O. Matos \& R.P. Oliveira 70 (holótipo HUEFS).

Pode ser reconhecida pelas folhas oval-lanceoladas e amplexicaules, com lâmina pilosa e tricomas longos nas margens, base da bainha densamente pilosa, lema do antécio superior piloso no ápice e cotilédone protuberante. Seus espécimes foram inicialmente identificados como Dichanthelium cumbucanum, da qual difere por caracteres micro e macromorfológicos e distribuição geográfica: $D$. arenicola apresenta bainha pilosa com tricomas longos (vs. densamente pilosa com tricomas curtos em D. cumbucanum), lâmina oval- lanceolada a lanceolada (vs. lanceolada), tricomas longos em toda a margem da lâmina foliar (vs. tricomas longos apenas na base da lâmina foliar), cotilédone protuberante (vs. levemente depresso) e hilo obovado (vs. punctiforme).

4. Dichanthelium assurgens (Renvoize) Zuloaga, Am. J. Bot. 90: 816. 2003.

Figuras 3G, H e 4; Renvoize (1982: fig. 3).

Planta provavelmente perene. Colmos até $2 \mathrm{~m}$ compr., eretos; nós glabros; entrenós 4-10 cm compr., glabros. Bainhas foliares $3-7 \mathrm{~cm}$ compr., não sobrepostas, pilosas com tricomas adpressos, sem glândulas, persistentes, margens ciliadas; lígula ca. 0,3 mm compr.; colo piloso. Lâminas $8-12 \times 0,7-1 \mathrm{~cm}$, linear-lanceoladas, não congestas no colmo, esparsamente pilosas em ambas as faces, sem glândulas, base atenuada, não amplexicaule, ápice agudo, margens escabras, planas. Panículas 12-15 × 7-10 cm, ramificadas, exsertas, paucifloras; ráquis flexuosa, glabra, sem glândulas; ramos de primeira ordem glabros, sem glândulas; pulvino glabro; pedicelo glabro. Espiguetas 2,7-3,3 × 0,5-0,7 mm, elipsoides, verdes, glabras ou esparsamente pilosas; gluma inferior 2,1-2,7 $\mathrm{mm}$ compr., $3 / 4-4 / 5$ do comprimento da espigueta, monomórfica, 3-nervada, glabra; entrenó entre as glumas inconspícuo; gluma superior 2,5-2,7 × 1,2-1,5 mm, 9-nervada, glabra; lema inferior 2,3-2,9 $\times$ ca. 1,3 $\mathrm{mm}$, 9-nervado, glabro; pálea inferior 1,8-2 × 0,3-0,7 $\mathrm{mm}$, lanceolada, hialina, esparsamente pilosa a glabra; flor inferior ausente; antécio superior 2,5-2,7 × 0,8-0,9 $\mathrm{mm}$, elipsoide, não inflado na base, estramíneo, glabro com tricomas no ápice do lema. Cariopses ca. 2,1 × 0,9 mm compr., elipsoides, marrons; hilo punctiforme.

Endêmica da Bahia, conhecida apenas dos arredores de Rio de Contas, a cerca de $1.000 \mathrm{~m}$ de altitude (Renvoize 1982, 1984; Zuloaga et al. 1993). F6: bordos de florestas.

Material examinado - Rio de Contas, $41^{\circ} 47^{\prime} \mathrm{W}, 13^{\circ} 33^{\prime} \mathrm{S}, 18$ jan. 1972, R.M. Harley et al. 15229 (holótipo CEPEC, foto HUEFS).

Conhecida apenas pelo material tipo, morfologicamente relacionada a Dichanthelium aequivaginatum, com representantes apresentando colmos longos, lâminas linear-lanceoladas, partes vegetativas e reprodutivas glabras, além de panículas longo-exsertas e laxas (Renvoize 1982; Zuloaga et al. 1993), diferindo pelos nós glabros (vs. pilosos em $D$. aequivaginatum), ráquis da inflorescência torcida na base (vs. não torcida), gluma inferior $3 / 4-4 / 5$ do comprimento da espigueta (vs. $1 / 2$ do comprimento da espigueta).

5. Dichanthelium barbadense Salariato, Morrone \& Zuloaga, Syst. Bot. 36: 53. 2011.

Figura 5; Salariato et al. (2011: fig. 1).

Planta perene. Colmos $15-40 \mathrm{~cm}$ compr., eretos; nós pilosos; entrenós 0,5-3 cm compr., pilosos. Bainhas foliares 1,2-3 cm compr., glabras, sem glândulas, persistentes, uma margem longo-ciliada em direção ao 
ápice, a outra glabra; lígula não vista; colo piloso. Lâminas 1-3 cm $\times$ 4-5 $\mathrm{mm}$, oval-lanceoladas a lanceoladas, não congestas no colmo, pilosas em ambas as faces com tricomas de base tuberculada ou esparsamente pilosas, sem glândulas, base subcordada, não amplexicaule, ápice agudo, margens escabras, involutas em direção ao ápice. Panículas 3-5 × 1-2 cm, ramificadas, paucifloras; ráquis glabra a esparsamente pilosa, sem glândulas; ramos de primeira ordem glabros, sem glândulas; pulvino piloso; pedicelo piloso. Espiguetas 2,8-3,2 × 1,2-1,4 mm, elipsoides, verdes ou arroxeadas, glabras; gluma inferior 1,2-1,6 mm compr., $\leq 1 / 2$ do comprimento da espigueta, monomórfica, 1 - ou 3-nervada, glabra; gluma superior tão longa quanto a espigueta, 9- ou 11-nervada, glabra a pilosa; lema inferior tão longo quanto a espigueta, 9-nervado, glabro a piloso; pálea inferior 2,4-2,6 $\times$ ca. 1,2 mm, lanceolada, hialina, glabra com margens cilioladas; flor inferior ausente; antécio superior 2,1-2,4 $\times$ 0,6-1,2 mm, elipsoide, não inflado na base, estramíneo, glabro com tricomas curtos no ápice do lema ou completamente glabro. Cariopses não vistas.

Endêmica da Bahia, restrita ao Pico do Barbado, em Abaíra, Chapada Diamantina, ocorrendo entre 1.800 e $2.400 \mathrm{~m}$ de altitude (Salariato et al. 2011). F6: campos rupestres, em solos pedregosos (Salariato et al. 2011).

Material selecionado - Abaíra, 15 ago. 1998, A.M. Giullietti et al. 1454 (ICN [foto]).

Dichanthelium barbadense coocorre com espécies de Apocloa Zuloaga \& Morrone e Renvoizea Zuloaga \& Morrone (Poaceae), além de Velloziaceae e Eriocaulaceae (Sariato et al. 2011). É uma espécie pouco conhecida, cujo material tipo não havia sido localizado até pouco tempo. Carece de estudos detalhados que possibilitem a melhor compreensão de sua identidade e relações com outras espécies do gênero, bem como maiores informações acerca de sua ecologia.

Assemelha-se morfologicamente a Dichanthelium congestum pelas panículas paucifloras e colmos se ramificando livremente, mas apresenta espiguetas glabras (vs. densamente pilosas em $D$. congestum) e gluma inferior $\leq 1 / 2$ do comprimento da espigueta, 1 - ou 3-nervada (vs. $\geq 3 / 4$ do comprimento da espigueta, 5- ou 7-nervada).

6. Dichanthelium cabrerae (Zuloaga \& Morrone) Zuloaga, Am. J. Bot. 90: 816. 2003.

Figuras 3I, J e 5; Zuloaga \& Morrone (1991a: fig. 3).

Planta perene. Colmos 25-40 cm compr., eretos; nós glabros ou pilosos com longos tricomas; entrenós $0,3-2 \mathrm{~cm}$ compr., pilosos. Bainhas foliares $0,5-2 \mathrm{~cm}$ compr., pilosas, sem glândulas, persistentes, margens pilosas; lígula ca. 0,2 mm compr.; colo piloso. Lâminas 1,7-4,5 cm × ca. $2 \mathrm{~mm}$, linear-lanceoladas, não congestas no colmo, pilosas em ambas as faces, sem glândulas, base atenuada, não amplexicaule, ápice agudo, margens densamente pilosas e escabras, decíduas na maturidade, involutas. Panículas 1,5-7 $\times$ 0,5-7 cm, ramificadas, exsertas, paucifloras; ráquis densamente pilosa na porção inferior, se não, glabra, sem glândulas; ramos de primeira ordem glabros, pilosos na base, sem glândulas; pulvino piloso a glabro; pedicelo glabro. Espiguetas 1,7-2,6 × 0,6-1,7 mm, elipsoides, verdes ou arroxeadas, pilosas; gluma inferior $0,7-1,6 \times$ $0,5-0,7 \mathrm{~mm}, \geq 1 / 2$ do comprimento da espigueta, monomórfica, 3-nervada, pilosa; gluma superior 1,6-2,4 $\times$ 0,9-1,1 mm, 9-nervada, pilosa; lema inferior 1,4-1,9 $\times$ 0,8-0,9 mm, 9-nervado, piloso; pálea inferior 1,1-1,8 $\times$ ca. $0,3 \mathrm{~mm}$, lanceolada, hialina, glabra; flor inferior ausente; antécio superior 1,6-2 × 0,6-0,9 mm, elipsoide, não inflado na base, estramíneo, glabro com microtricomas no apículo. Cariopses ca. 1,1 mm compr., obovoides, marrons; hilo oblongo.

Endêmica da Bahia, ocorre na Chapada Diamantina, entre 1.000 e $1.600 \mathrm{~m}$ de altitude (Zuloaga \& Morrone 1991a; Zuloaga et al. 1993). F5 e F6: campos rupestres, em solos pedregosos e áreas abertas.

Material selecionado - Abaíra, 13¹6'S, 415'', 14 jul. 1992, W. Ganev 646 (HUEFS); Palmeiras, 27 abr. 1997, R.M. Harley et al.

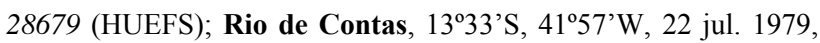
S.A. Mori et al. 12475 (holótipo CEPEC).

Pode ser facilmente reconhecida por ser ramificada apenas na base, além da presença de lâminas foliares com margens involutas. Foi descrita a partir de um material inicialmente identificado como Dichanthelium stipiflorum (Zuloaga et al. 1991a), da qual distingue-se principalmente pelas características vegetativas, uma vez que apresenta lâminas lanceoladas, densamente pilosas (vs. oval-lanceoladas, glabras a curto pilosas em $D$. stipiflorum), espiguetas densamente pilosas (vs. esparsamente pilosas) e hilo oblongo (vs. punctiforme). Além disso, compartilha o aspecto vegetativo e espigueta de comprimento semelhante a $D$. aciculare (Desv. ex Poir.) Gould \& C.A.Clark, que, no entanto, apresenta espiguetas obovoides, sem pálea inferior (Zuloaga et al. 1993).

\section{Dichanthelium congestum (Renvoize) Zuloaga,} Am. J. Bot. 90: 816. 2003.

Figuras 3K, L e 5; Renvoize (1982: fig. 6A-D).

Planta perene. Colmos $30-50 \mathrm{~cm}$ compr., eretos; nós pilosos; entrenós 1,5-4,5 cm compr., densamente pilosos. Bainhas foliares $0,5-2,5 \mathrm{~cm}$ compr., densamente pilosas a glabrescentes, sem glândulas, persistentes ou caducas, margens membranosas; lígula 0,7-1 mm compr.; colo densamente piloso. Lâminas 1$5 \mathrm{~cm} \times 2-5 \mathrm{~mm}$, linear-lanceoladas, congestas no colmo, densamente pilosas em ambas as faces, sem glândulas, base atenuada, não amplexicaule, ápice agudo, margens pilosas, involutas. Panículas 2-4,5 compr., não ramificadas, com a base incluída nas folhas superiores, paucifloras com 2 ou 3(-9) espiguetas por panícula; ráquis pilosa, sem glândulas; pulvino não visto; pedicelo piloso. Espiguetas 2,3-3,2 $\times$ ca. $1 \mathrm{~mm}$, elipsoides, verdes, pilosas; gluma inferior $2,2-2,6 \mathrm{~mm}$ compr., $\geq 3 / 4$ do comprimento da espigueta, monomórfica, 5- ou 7nervada, pilosa; gluma superior 2,2-2,6 × 0,8-1 mm, 9nervada, pilosa; lema inferior 2-2,4 × 0,8-1 mm, 9- 
nervado, piloso; pálea inferior $1,5-1,7 \times$ ca. $0,4 \mathrm{~mm}$, lanceolada, hialina, glabra com margens ciliadas; flor inferior ausente; antécio superior $2-2,4 \times$ ca. $0,8 \mathrm{~mm}$, elipsoide, não inflado na base, estramíneo, glabro com tricomas esparsamente distribuídos no ápice do lema. Cariopses $1-1,5 \times$ ca. $0,5 \mathrm{~mm}$, elipsoides, marrons; hilo oblongo.

Endêmica da Bahia, conhecida apenas de Minas do Mimoso, ocorrendo a cerca de $1.000 \mathrm{~m}$ de altitude (Renvoize 1982, 1984; Zuloaga et al. 1993). F3: campos rupestres, em solos pedregosos.

Material examinado - Minas do Mimoso, 10²0'S, 41 ${ }^{\circ} 20^{\prime} \mathrm{W}, 6$ mar. 1974, R.M. Harley et al. 16869 (holótipo CEPEC).

Pode ser reconhecida pelos colmos densamente ramificados, entrenós, bainhas, lâminas, panículas e espiguetas densamente pilosas, além de panículas paucifloras com a base incluída nas folhas superiores e pouco ramificadas. Assim como Dichanthelium cabrerae, apresenta as margens das folhas involutas e tricomas em todo o corpo da planta, distinguindo-se pelas panículas paucifloras, incluídas na base das folhas e contraídas (vs. multifloras, exsertas e laxas em D. cabrerae), gluma inferior $\geq 3 / 4$ do comprimento da espigueta (vs. gluma inferior menor, cobrindo ca. $1 / 2$ do comprimento da espigueta).

8. Dichanthelium cumbucanum (Renvoize) Zuloaga, Am. J. Bot. 90: 816. 2003.

Figuras 1C, 2B, 3M, N e 6; Renvoize (1982: fig. 7C, D).

Planta perene. Colmos até $35 \mathrm{~cm}$ compr., decumbentes; nós pilosos; entrenós 1-2,8 cm compr., densamente pilosos. Bainhas foliares 1-2 cm compr., densamente pilosas, sem glândulas, persistentes, uma margem longo ciliada, a outra curto-pilosa; lígula 0,4 $0,6 \mathrm{~mm}$ compr.; colo piloso. Lâminas $0,5-3,5 \times 0,1-1,7$ $\mathrm{cm}$, lanceoladas, não congestas no colmo, glabras ou densamente pilosas em ambas as faces, sem glândulas, base cordada, amplexicaule, ápice agudo, margens longo-ciliadas na base das lâminas ou pilosas, planas. Panículas 1-6 × 1-4 cm, ramificadas, exsertas ou com a base incluída nas folhas superiores, paucifloras; ráquis esparsamente pilosa a pilosa, sem glândulas; ramos de primeira ordem pilosos, sem glândulas; pulvino piloso; pedicelo esparsamente piloso. Espiguetas 2,1-3 × 0,7$0,9 \mathrm{~mm}$, solitárias ou pareadas, elipsoides, verdes ou tingindas de roxo, curto-pilosas; gluma inferior 1-1,8 $\times$ 0,4-0,8 $\mathrm{mm}, 1 / 2$ do comprimento da espigueta, monomórfica, (1)3-nervada, pilosa; gluma superior 1,52,2 $\times$ ca. $0,7 \mathrm{~mm}, 7$ - ou 9-nervada, curto-pilosa; lema inferior 1,5-1,8 × ca. $0,5 \mathrm{~mm}, 7$ - ou 9-nervado, curtopiloso; pálea inferior $1,2-1,5 \times 0,2-0,3 \mathrm{~mm}$, linearlanceolada, hialina, glabra; flor inferior ausente; antécio superior $1,5-2,4 \times 0,5-0,8 \mathrm{~mm}$, elipsoide, não inflado na base, estramíneo, glabro. Cariopses $1-1,9 \times 0,3-0,5$ $\mathrm{mm}$, elipsoides, marrons; hilo punctiforme.

Endêmica da Bahia, conhecida somente da Chapada Diamantina, entre 900 a $1.400 \mathrm{~m}$ de altitude (Renvoize 1982, 1984; Zuloaga et al. 1993). E7, F4, F5 e F6: campos rupestres, em solos arenosos e pedregosos.
Material selecionado - Andaraí, $12^{\circ} 15^{\prime} \mathrm{S}, 41^{\circ} 18^{\prime} \mathrm{W}, 20$ nov. 1983, L.R. Noblick et al. 2870 (HUEFS); Ibicoara, 13¹3'S, 41ํ'16'W, 20 set. 2012, K.M. Pimenta 456 (HUEFS); Lençóis, $12^{\circ} 37^{\prime}$ S, 41 ${ }^{\circ} 26^{\prime} \mathrm{W}$, dez. 2018, A.O. Matos et al. 74 (HUEFS); Morro do Chapéu, $11^{\circ} 37^{\prime} \mathrm{S}, 41^{\circ} 00^{\prime} \mathrm{W}, 22$ set. 2016, A.A.S. Mascarenhas et

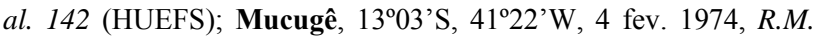
Harley et al. 15930 (holótipo CEPEC, isótipo MO [foto]); Palmeiras, jun. 1996, N.N.A. Santos s.n. (HUEFS 10055); Rio de Contas, $13^{\circ} 31^{\prime} \mathrm{S}, 41^{\circ} 54^{\prime} \mathrm{W}, 16$ out. 2012, R.P. Oliveira et al. 2155 (HUEFS).

É reconhecida pelas folhas lanceoladas com a base cordada, geralmente crescendo em tufos. Foi descrita a partir de materiais de Mucugê e Rio de Contas, no sul da Chapada Diamantina, a partir de plantas com inflorescências incluídas nas folhas superiores e folhas com base cordada. Entretanto, Zuloaga et al. (1993) passaram a considerar uma distribuição geográfica mais ampla, também incluindo na espécie plantas com inflorescências parcialmente exsertas e folhas descritas como amplexicaules.

Muitos materiais têm sido inadvertidamente incluídos nas coleções de Dichanthelium cumbucanum, principalmente por semelhanças gerais, mas a delimitação da espécie ainda é confusa e carece de estudos aprofundados para definir melhor seus limites em relação às espécies relacionadas. Dichanthelium arenicola, por exemplo, foi recentemente descrita a partir de materiais inicialmente identificados como $D$. cumbucanum (veja os comentários daquela espécie para uma comparação morfológica).

Dichanthelium cumbucanum também é frequentemente confundida com D. stipiflorum, indicada por Zuloaga et al. (1993) como possivelmente coespecífica. Entretanto, as duas espécies podem ser distinguidas pelas bainhas foliares com uma margem longo-ciliada e outra curto-pilosa em $D$. cumbucanum (vs. ambas as margens longo-ciliadas em $D$. stipiflorum) e inflorescências curto-exsertas ou incluídas nas folhas superiores (vs. longo-exsertas).

9. Dichanthelium hebotes (Trin.) Zuloaga, Am. J. Bot. 90: 816. 2003.

Figuras 3O, P e 6; Zuloaga et al. (1993: fig. 33).

Planta perene. Colmos 30-90 cm compr., decumbentes; nós pilosos; entrenós 3,5-15 cm compr., pilosos. Bainhas foliares $2,5-7,5 \mathrm{~cm}$ compr., pilosas, sem glândulas, persistentes, uma margem ciliada, a outra glabra; lígula ca. 0,3 mm compr.; colo piloso. Lâminas $4,5-15 \times 0,7-2,3 \mathrm{~cm}$, lanceoladas, não congestas no colmo, pilosas em ambas as faces, ou com face adaxial glabra, sem glândulas, base estreita, às vezes cordada, não amplexicaule, ápice atenuado, margens escabras, planas. Panículas 7-22 × 4,5-11 cm, ramificadas, longo-exsertas, multifloras; ráquis curtopilosa, sem glândulas; ramos de primeira ordem glabros ou esparsamente pilosos, sem glândulas; pulvino piloso; pedicelo piloso. Espiguetas 1,5-1,9 × 0,6-0,9 mm, elipsoides, verdes, glabras a esparsamente pilosas na base; gluma inferior 0,7-1,5 mm compr., $1 / 2-3 / 4$ do comprimento da espigueta, dimórfica, 1- ou 3-nervada 

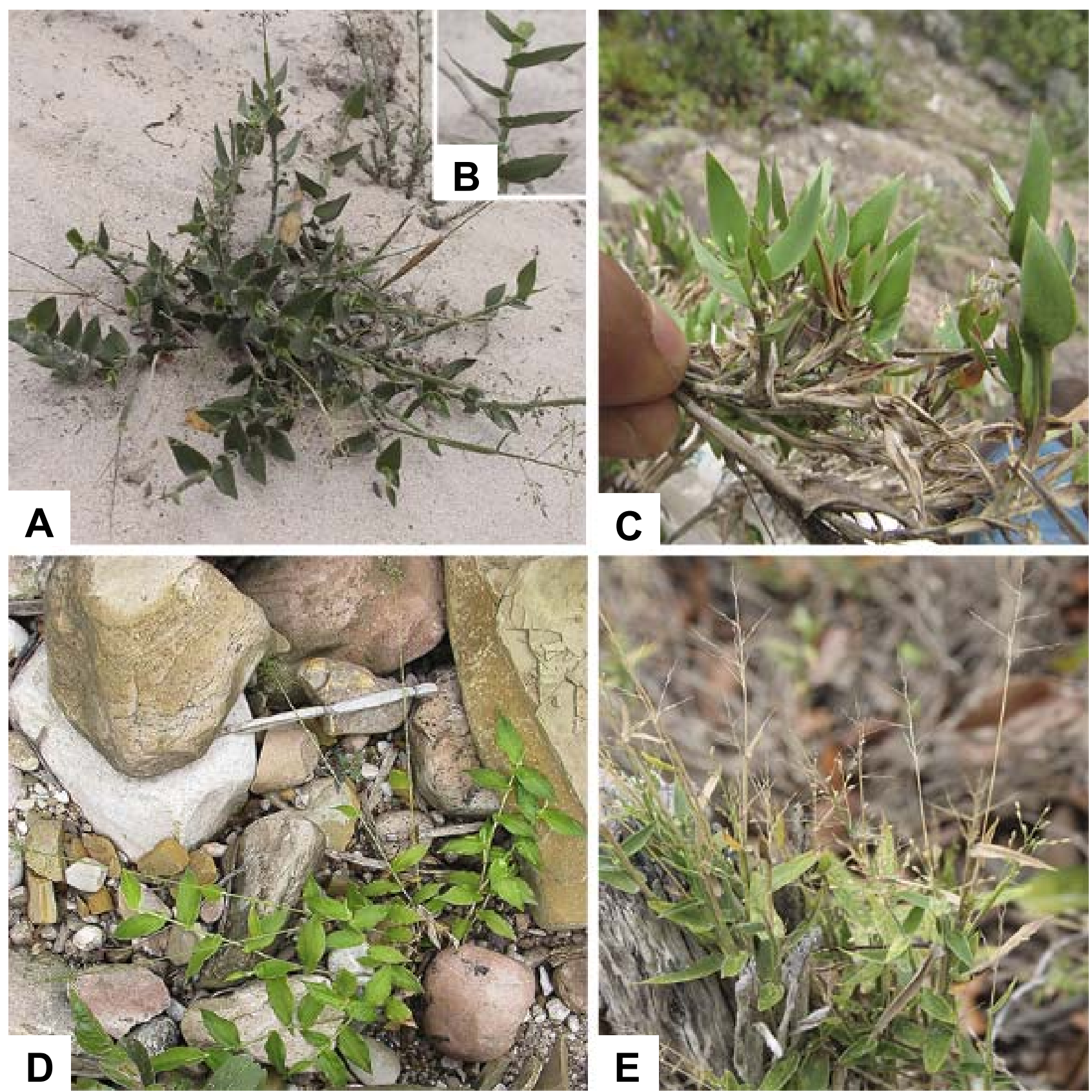

Figura 1. A, B. Dichanthelium arenicola: A- hábito e hábitat em solo arenoso; B- folhas amplexicaules em detalhe. C. D. cumbucanum: hábito com inflorescência parcialmente exserta. D. D. sciurotoides: hábito e hábitat em solo rochoso. E. D. stipiflorum: hábito com inflorescências exsertas (Fotos: A, B e D- R.P. Oliveira; C- J.F.C. Oliveira; E- A.O. Matos).

ou 7-nervada, glabra; gluma superior $1,4-1,7 \mathrm{~mm}$ compr., 9-nervada, glabra a esparsamente pilosa; lema inferior 1,6-1,8 $\mathrm{mm}$ compr., 9-nervado, glabro a esparsamente piloso; pálea inferior $0,7-1,2 \times$ ca. 0,3 $\mathrm{mm}$, lanceolada, hialina, glabra; flor inferior ausente; antécio superior $1,3-1,7 \times 0,7-0,8 \mathrm{~mm}$, elipsoide, não inflado na base, estramíneo quando jovem, marrom ou preto na maturidade, glabro com tricomas no ápice do lema. Cariopses ca. $1 \times 0,6 \mathrm{~mm}$, elipsoides, marrons; hilo punctiforme.

Amplamente distribuída na América do Sul, encontrada na Venezuela, Equador, Bolívia e Brasil, de 500 a $800 \mathrm{~m}$ de altitude (Zuloaga et al. 1993). No Brasil, é distribuída nas Regiões Nordeste, Sudeste e Sul, ocorrendo nas mais diversas fitofisionomias associadas ao Cerrado e Mata Atlântica (Delfini et al. 2020). H8: florestas submontanas, ocorrendo em bordos de floresta.

Material examinado - Camacan, $15^{\circ} 23^{\prime} \mathrm{S}, 30^{\circ} 33^{\prime} \mathrm{W}, 24$ nov. 2007, A.C. Mota 191 (HUEFS).

Assemelha-se a Dichanthelium aequivaginatum na aparência geral, apresentando colmos eretos, inflorescências abertas, multifloras e gluma inferior não abraçando a superior. Pode ser facilmente distinguida dela, no entanto, pela pilosidade no corpo da planta (vs. corpo da planta glabro em $D$. aequivaginatum) e antécio superior escuro na maturidade (vs. antécio estramíneo). É a única espécie do gênero a apresentar dimorfismo na gluma inferior, que pode ser pequena e 1- ou 3-nervada (Fig. 3O) ou longa e 7-nervada (Fig. 3Q). Essa variação acontece num mesmo indivíduo e pode ser encontrada, 

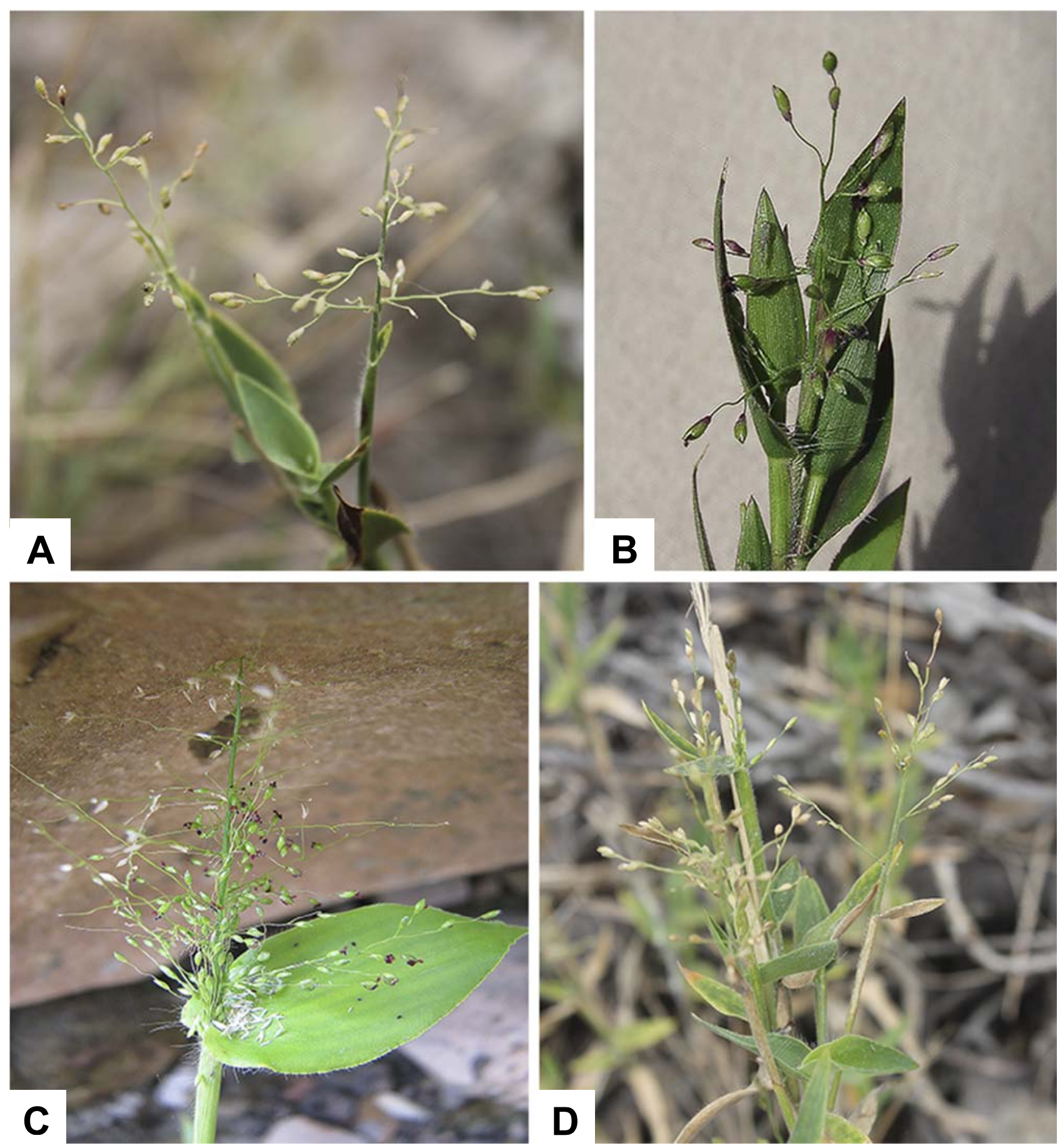

Figura 2. Inflorescências de Dichanthelium em detalhe: A- D. arenicola; B- D. cumbucanum; C- D. sciurotoides; D- D. stipiflorum (Fotos: A, C- R.P. Oliveira; B, D- A.O. Matos).

inclusive, no mesmo ramo da inflorescência em antécios jovens ou maduros.

10.Dichanthelium pycnoclados (Tutin) Davidse, Monogr. Syst. Bot. Missouri Bot. Gard. 45: 1258. 1993.

Figura 6; Zuloaga et al. (1993: fig. 34).

Planta perene. Colmos 12-60 cm compr., decumbentes; nós pubescentes; entrenós 3-15 cm compr., glabros a pilosos. Bainhas foliares $2-5 \mathrm{~cm}$ compr., glabras a pilosas, sem glândulas, persistentes, margens longo-ciliadas; lígula $(0,2-) 1-1,5 \mathrm{~cm}$ compr.; colo piloso. Lâminas $2-4,5(-12) \times 0,5-1,8 \mathrm{~cm}$, lanceoladas a oval-lanceoladas, não congestas no colmo, glabras a densamente pilosas, sem glândulas, base cordada, não amplexicaule, ápice agudo, margens escabras e pilosas na base, planas. Panículas 3-6(-10) $\times 1,5-6 \mathrm{~cm}$, ramificadas, exsertas, multifloras; ráquis glabra ou pilosa com longos tricomas de base tuberculada, sem glândulas; ramos de primeira ordem glabros ou pilosos, sem glândulas; pulvino glabro ou piloso; pedicelo glabro ou piloso. Espiguetas 2,2-3($3,3) \times 0,8-0,9 \mathrm{~mm}$, elipsoides, verdes, glabras ou pilosas; gluma inferior $(0,7-) 1,2-1,8 \mathrm{~mm}$ compr., $1 / 2-3 / 4$ 


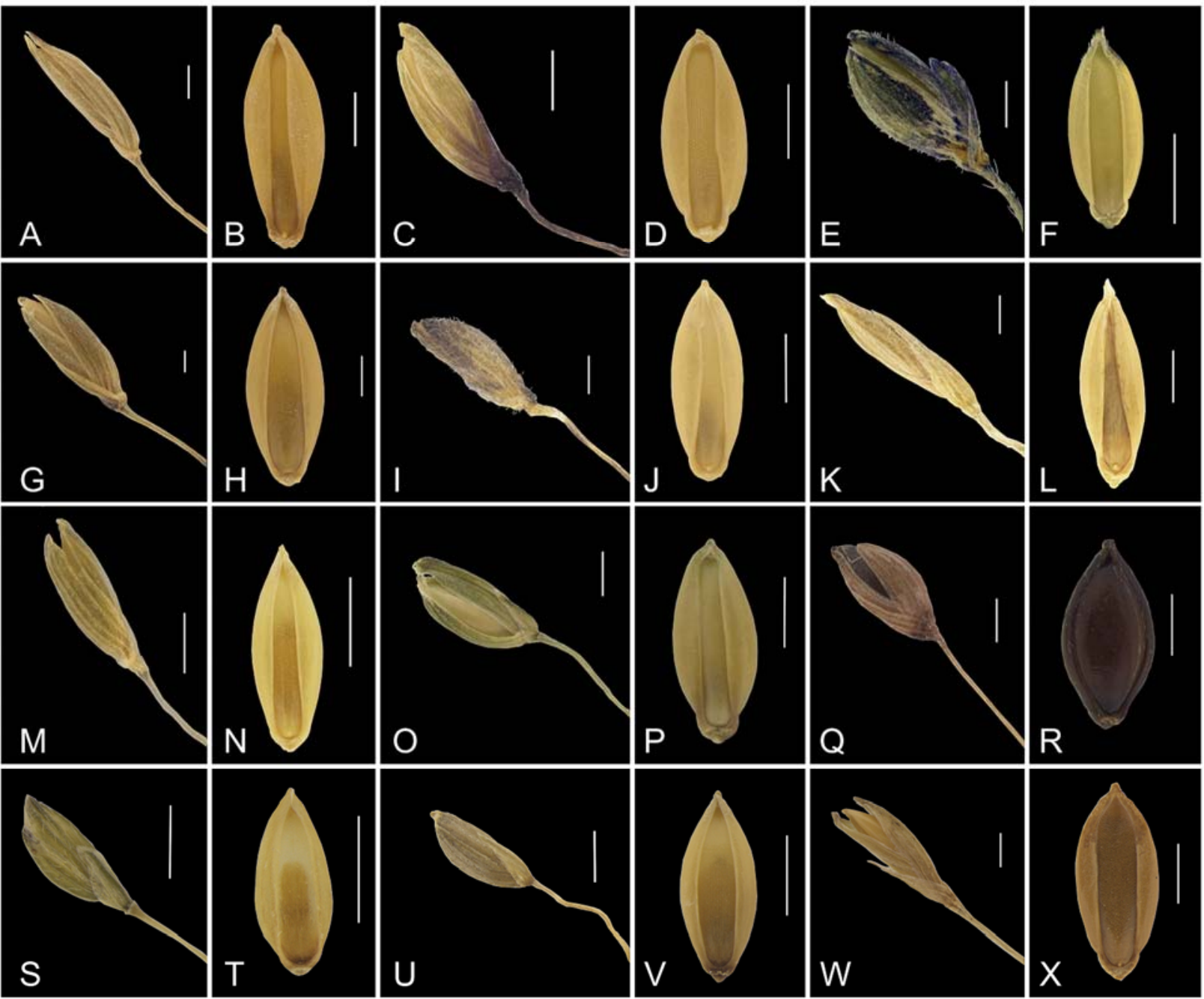

Figura 3. Espiguetas e antécios superiores de Dichanthelium: A, B- D. adenorhachis (Mori 12451a); C, D- D. aequivaginatum (Zuloaga 2469); E, F- D. arenicola (Matos 70); G, H- D. assurgens (Harley 15930); I, J- D. cabrerae (Mori 12475); K, L- D. congestum (Harley 16869); M, N- D. cumbucanum (Harley 15930); O, P- D. hebotes imaturo (Mota 191); Q, R- D. hebotes maduro (Mota 191); S, T- D. sciurotis (Guedes 7005); U, V-D. sciurotoides (Miranda 306); W, X- D. stipiflorum (Harley 17019).

do comprimento da espigueta, monomórfica, 3(5)nervada, glabra ou pilosa; gluma superior 1,9-2,7 $\times$ ca. 0,6 mm compr., 9-nervada, glabra ou pilosa; lema inferior 1,6-2,7 × ca. 0,7 mm, 7- ou 9-nervado, glabro a piloso; pálea inferior $1,5-1,8 \times$ ca. $0,3 \mathrm{~mm}$, linearlanceolada, hialina, glabra; flor inferior ausente; antécio superior $1,8-2,1 \times$ ca. $0,8 \mathrm{~mm}$, elipsoide, não inflado na base, estramíneo, escabro e piloso. Cariopses ca. 1,5 × 0,8 mm compr., elipsoides, marrons; hilo punctiforme.

Amplamente distribuída ao longo da América do Sul, no Equador, Peru, Venezuela, Guiana, Suriname e Brasil, entre 500 e $2.600 \mathrm{~m}$ de altitude (Zuloaga et al. 1993). No Brasil, está distribuída nas Regiões Nordeste e Sudeste, em áreas de Caatinga e Mata Atlântica (Delfini et al. 2020). F3 e F4: campos rupestres e áreas de vegetação aberta na Caatinga.

Material examinado - Morro do Chapéu, $11^{\circ} 26^{\prime} \mathrm{S}, 41^{\circ} 11^{\prime} \mathrm{W}$, 1 jul. 2007, E. Melo et al. 4955 (HUEFS); Sento Sé, 10²18'S, 412'' 'W, 8 set. 2016, L.P. Queiroz et al. 16282 (HUEFS).
Foi descrita a partir de um material das Guianas como planta perene, com lâminas foliares de 4,5-8,5 × 0,5-1,3 cm, linear-lanceoladas, lígula curta e ciliada, panículas 6-9 × 5-7 cm, espiguetas de 3,5 cm compr., com gluma superior e lema inferior multinervados e pilosos, além do ápice do lema superior piloso. Tutin (1934) também indicou inflorescências contraídas antes da floração e abertas depois. O conceito da espécie foi revisado por Zuloaga et al. (1993) e uma ampla variação morfológica passou a ser aceita em sua circunscrição, tanto nos caracteres vegetativos quanto reprodutivos, incluindo outras três espécies descritas para a Venezuela sob sua sinonímia (Zuloaga et al. 1993). Segundo esse conceito, a espécie apresenta grande variação no comprimento e largura dos entrenós, lígulas, lâminas foliares, panículas e espiguetas (veja descrição) e na pilosidade, com a maioria das estruturas podendo ser glabra ou pilosa (Zuloaga et al. 1993).

Tutin (1934) afirmou que Dichanthelium pycnoclados (como Panicum pycnoclados Tutin) 


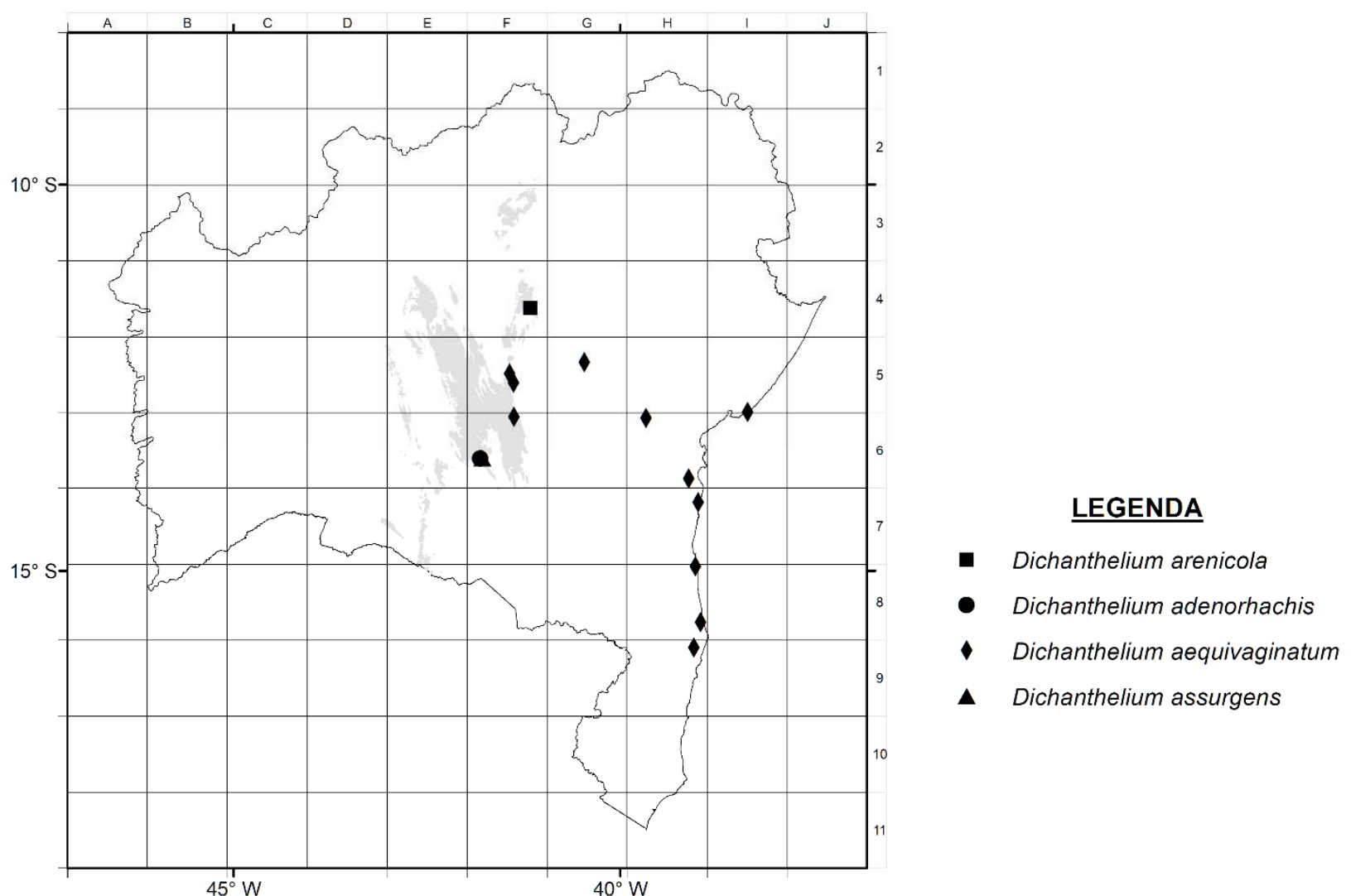

Figura 4. Mapa de distribuição de Dichanthelium arenicola, D. adenorhachis, D. aequivaginatum e D. assurgens no estado da Bahia; em cinza, a região da Chapada Diamantina (acima de 900 m s.n.m.).

possuiria afinidades com Panicum ovuliferum Trin. e $P$. cordovense E.Fourn., que atualmente pertencem ao gênero Parodiophyllochloa Zuloaga \& Morrone (Morrone et al. 2008). Zuloaga et al. (1993), por outro lado, compararam a espécie com $D$. stipiflorum, a qual poderia ser, inclusive, uma variante de $D$. pycnoclados. Dada a grande variação morfológica atualmente aceita nessa espécie, suas características acabam se sobrepondo com a maioria das espécies de Dichanthelium da Bahia. Como não foi possível analisar espécimes representativos ao longo de toda a sua distribuição na América do Sul, adotamos a circunscrição ampla atualmente aceita, mas ressaltamos a necessidade de estudos para esclarecer os limites taxonômicos de D. pycnoclados.

11.Dichanthelium sciurotis (Trin.) Davidse, Novon 2: 104. 1992.

Figuras 3S, T e 7; Zuloaga \& Morrone (1991b: fig. 1I-O).

Planta anual. Colmos 5-25 cm compr., decumbentes; nós densamente pilosos; entrenós $2-8 \mathrm{~cm}$ compr., pilosos. Bainhas foliares $1-5 \mathrm{~cm}$ compr., pilosas, sem glândulas, persistentes, margens ciliadas; lígula ca. 0,4 mm compr.; colo piloso. Lâminas 1,5-9 $\times$ $0,8-2,8 \mathrm{~cm}$, oval-lanceoladas, não congestas no colmo, pilosas em ambas as faces, com tricomas de base tuberculadas em glândulas, base cordada, amplexicaule, ápice atenuado, margens ciliadas, planas. Panículas 2
$7 \times 1-5 \mathrm{~cm}$, ramificadas, multifloras; ráquis pilosa com tricomas de base tuberculada, sem glândulas; ramos de primeira ordem glabros ou esparsamente pilosos, sem glândulas; pulvino piloso; pedicelo glabro. Espiguetas 1,5-1,7 $\times 0,7-0,8 \mathrm{~mm}$, solitárias, elipsoides, verdes, pilosas; gluma inferior $0,3-0,4 \mathrm{~mm}$ compr., $\leq 1 / 2$ do comprimento da espigueta, monomórfica, enérvia ou 1nervada, pilosa; gluma superior $1,4-1,5 \mathrm{~cm} \times \mathrm{ca} .7 \mathrm{~mm}$, 5(7)-nervada, pilosa; lema inferior $1,5-1,6 \mathrm{~cm} \times$ ca. 8 $\mathrm{mm}, 5$-nervado, piloso; pálea inferior ca. $0,9 \times 0,2 \mathrm{~mm}$, lanceolada, hialina, glabra; flor inferior ausente; antécio superior 1,4-1,5 × 0,5-0,7 mm, elipsoide, não inflado na base, estramíneo, glabro. Cariopses $1-1,2 \times$ ca. $0,5 \mathrm{~mm}$, obovoides, marrons; hilo punctiforme.

Endêmica do Brasil, encontrada nas Regiões Nordeste, Sul e Sudeste, em ambientes de Caatinga e Mata Atlântica (Delfini et al. 2020). E2, G3, H4, H5, H6, H7, H8, H9 e I5: caatingas e florestas abertas, ocorrendo em solos arenosos.

Material selecionado - Canavieiras, $15^{\circ} 33^{\prime} \mathrm{S}, 38^{\circ} 58^{\prime} \mathrm{W}, 5$ jun. 2009, F.M. Ferreira \& M.L. Carvalho 2129 (HUEFS); Conceição do Coité, $11^{\circ} 30^{\prime} \mathrm{S}, 39^{\circ} 12^{\prime} \mathrm{W}, 7$ set. 2012, D.N. Carvalho 88 (HUEFS); Cruz das Almas, jun. 1951, G.C.P. Pinto 51-203 (ALCB); Eunápolis, $16^{\circ} 22^{\prime}$ S, $39^{\circ} 00^{\prime} \mathrm{W}, 7$ nov. 2000, M.L.S. Guedes et al. 7558 (ALCB); Feira de Santana, $12^{\circ} 15^{\prime}$ S, $38^{\circ} 58^{\prime} \mathrm{W}, 7$ set. 1983 , L.R. Noblick 2735 (HUEFS); Itacaré, $14^{\circ} 18^{\prime} \mathrm{S}, 39^{\circ} 15^{\prime} \mathrm{W}, 1$ ago. 2012, C. Snak et al. 1026 (RB); Mata de São João, 12²9'S, $38^{\circ} 18^{\prime} \mathrm{W}, 1$ dez. 1982, L.R. Noblick et al. 2328 (HUEFS); 


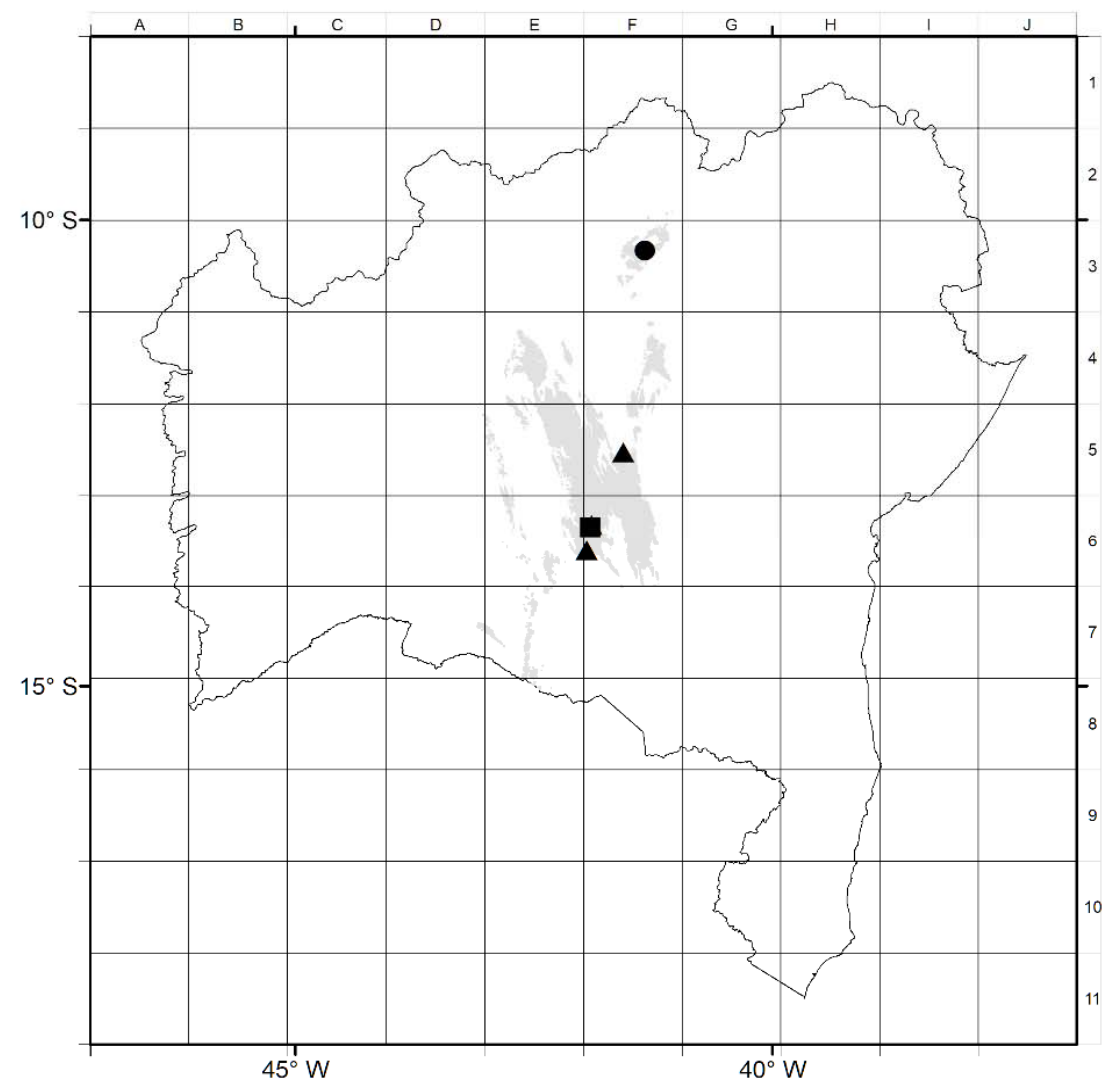

\section{LEGENDA}

Dichanthelium barbadense

\ Dichanthelium cabrerae

- Dichanthelium congestum

Figura 5. Mapa de distribuição de Dichanthelium barbadense, D. cabrerae e D. congestum no estado da Bahia; em cinza, a região da Chapada Diamantina (acima de 900 m s.n.m.).

Pindobaçu, $10^{\circ} 44^{\prime} \mathrm{S}, 40^{\circ} 21^{\prime} \mathrm{W}, 20$ dez. 1999, M.L.S. Guedes et al. 7656 (ALCB); Presidente Tancredo Neves, $14^{\circ} 45 \mathrm{~S}, 39^{\circ} 35^{\prime} \mathrm{W}, 31$ ago. 2014, N.E. Oliveira 288 (RB); Remanso, $09^{\circ} 44^{\prime}$ 'S, $42^{\circ} 23^{\prime} \mathrm{W}$, mar. 2000, M.L.S. Guedes et al. 7005 (ALCB, HUEFS); Saubara, 18 out. 2017, A.M. Miranda et al. 6830 (ALCB, HUEFS, RB); Una, out. 1951, G.C.P. Pinto 51-330 (ALCB).

Comum na Bahia, é frequentemente confundida com Dichanthelium sciurotoides, com materiais das duas espécies misturados em coleções de herbário. Entretanto, D. sciurotis apresenta distribuição significativamente mais restrita, podendo ser distinguida por possuir lema inferior e gluma superior 5(7)-nervados (vs. lema inferior e gluma superior 7- ou 9-nervados em D. sciurotoides) e cariopses obovoides (vs. elipsoides).

\section{Dichanthelium sciurotoides (Zuloaga \& Morrone)}

Davidse, Novon 2: 104. 1992.

Figuras 1D, 2C, 3U, V e 7; Zuloaga \& Morrone (1991b: fig. $1 \mathrm{~A}-\mathrm{G}$ ).

Planta anual. Colmos até $50 \mathrm{~cm}$ compr., decumbentes; nós densamente pilosos; entrenós 2,5-4,5 cm compr., glabros. Bainhas foliares $2-4 \mathrm{~cm}$ compr., pilosas na base com tricomas de base tuberculada e glabras em direção ao ápice, sem glândulas, persistentes, uma margem ciliada e outra glabra; lígula ca. 0,2 mm compr.; colo piloso. Lâminas $4-8 \times 1-3,5$ $\mathrm{cm}$, oval-lanceoladas, não congestas no colmo, pilosas na face abaxial, ou densamente pilosas em ambas as faces, ciliadas na face adaxial, sem glândulas, base cordada, amplexicaule, ápice agudo, margens escabras e ciliadas com tricomas tuberculosos. Panículas 5,5-9 $\times$ 4-5 cm, ramificadas, exsertas, multifloras; ráquis pilosa, sem glândulas; ramos de primeira ordem glabros, sem glândulas; pulvino piloso; pedicelo glabro. Espiguetas 1,3-1,9 × 0,5-1 mm, elipsoides, verdes, curto-pilosas; gluma inferior $0,5-0,6 \mathrm{~mm}$ compr., geralmente $1 / 3$ do comprimento da espigueta, monomórfica, 1- ou 3nervada, curto-pilosa; gluma superior 1,2-1,8 $\times 0,5-0,8$ mm, 7- ou 9-nervada, curto-pilosa; lema inferior 1,3-1,8 $\times$ 0,6-1 mm, 7- ou 9-nervado, curto-piloso; pálea inferior $0,6-1,2 \times 0,2-0,3 \mathrm{~mm}$, lanceolada, hialina, glabra; flor inferior ausente; antécio superior 1-1,6 $\times$ 0,4-0,7 mm, elipsoide, não inflado na base, estramíneo, glabro. Cariopses $0,9-1,1 \times 0,3-0,7 \mathrm{~mm}$, elipsoides, marrons; hilo punctiforme.

Distribuída de Belize e Panamá a Bolívia e Brasil, ocorrendo entre 100 e $1.400 \mathrm{~m}$ de altitude (Zuloaga \& Morrone 1991b; Zuloaga et al. 1993). No Brasil, ocorre nas Regiões Nordeste, Sudeste e Sul, em áreas de Cerrado e Mata Atlântica (Delfini et al. 2020). F4, F6, G6, H5, H6, H7, H8 e I5: campos rupestres e florestas, em solos arenosos e pedregosos.

Material selecionado - Abaíra, $41^{\circ} 38^{\prime} \mathrm{W}, 12^{\circ} 27^{\prime} \mathrm{S}, 23$ out. 1999, E.B. Miranda et al. 306 (HUEFS); Camacan, 15²3'S, $39^{\circ} 33^{\prime}$ W, 30 jun. 2007, A.C. Mota 73 (HUEFS); Candeias, ago. 


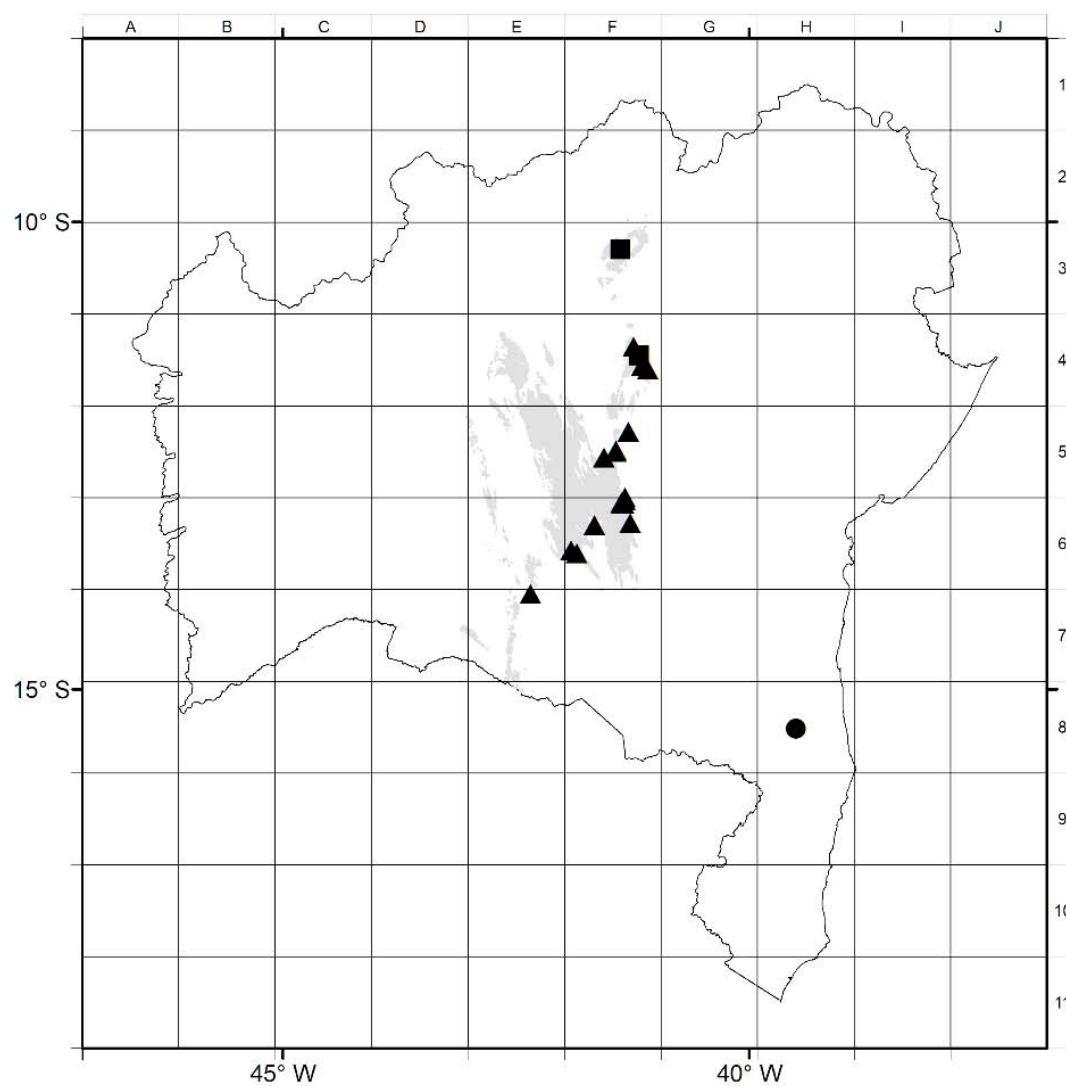

\section{LEGENDA}

- Dichanthelium cumbucanum

- Dichanthelium hebotes

- Dichanthelium pycnoclados

Figura 6. Mapa de distribuição de Dichanthelium cumbucanum, D. hebotes e D. pycnoclados no estado da Bahia; em cinza, a região da Chapada Diamantina (acima de 900 m s.n.m.).

1974, G.C.P. Pinto 42345 (ALCB); Cruz das Almas, 120'S, $39^{\circ} 06^{\prime} \mathrm{W}, 29$ set. 2010, L.Y.S. Aona et al. 1370 (HURB); Entre Rios, $12^{\circ} 10^{\prime}$ S, $37^{\circ} 58^{\prime} \mathrm{W}, 3$ set. 2014, A.V. Popovkin 1779 (HUEFS); Ibirapitanga, $13^{\circ} 54^{\prime} \mathrm{S}, 39^{\circ} 27^{\prime} \mathrm{W}, 26$ nov. 2011, R.P. Oliveira et al. 2110 (HUEFS); Igrapiúna, 13ํำ'S, 39 $07^{\circ}$ 'W, 29 jul. 2008, K.M. Pimenta 125 (HUEFS); Itacaré, $14^{\circ} 16^{\prime} \mathrm{S}, 38^{\circ} 49^{\prime} \mathrm{W}, 27$ jan. 2012 R.P. Oliveira \& M.C. Dorea 2137 (HUEFS); Jacobina, 11 $05^{\circ}$ 'S, 40³8'W, 2 mar. 1974, R.M. Harley 16636 (RB); Jiquiriçá, 1317'S, 39'23'W, 3 set. 2018, T.T. Silva 281 (HURB); Lençóis, 12²7'S, 41'26'W, dez. 2018, A.O. Matos \& J. Carneiro 75 (HUEFS); Maracás, $13^{\circ} 24^{\prime}$ S, $40^{\circ} 24^{\prime} \mathrm{W}, 11$ mar. 2008, M.C. Dorea 67

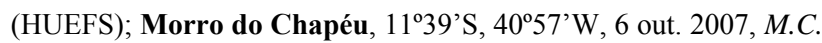
Dorea et al. 50 (HUEFS); Mucugê, $12^{\circ} 43^{\prime}$ S, 41 ${ }^{\circ} 30^{\prime} \mathrm{W}, 1$ nov. 2011, R.P. Oliveira et al. 2004 (HUEFS); Santa Teresinha, 12 $50^{\prime}$ 'S, 39'29'W, 2 set. 2015, G. Costa et al. 1462 (HUEFS, HURB); Uruçuca, $14^{\circ} 25^{\prime}$ 'S, $39^{\circ} 01^{\prime} \mathrm{W}, 25$ ago. 1992, A.M. Amorim et al. 661 (CEPEC).

Material adicional examinado - BRASIL. MINAS GERAIS Diamantina, Cristais, 13 maio 1931, Z'lexia 5819 (holótipo MO [foto]).

Essa espécie apresenta ampla distribuição na América do Sul. Dichanthelium sciurotoides foi descrita em 1992 baseada em um espécime do estado de Minas Gerais (Zuloaga \& Morrone 1991b), e é frequentemente confundida com $D$. sciurotis, espécie com a qual é morfologicamente relacionada (veja comparações morfológicas nos comentários da espécie anterior).
13. Dichanthelium stipiflorum Renvoize (Zuloaga), Am. J. Bot. 90(5): 817. 2003.

Figuras 1E, 2D, 3W, X e 7; Renvoize (1982: fig. 7C-D).

Planta anual. Colmos 20-120 cm compr., decumbentes na base; nós densamente pilosos; entrenós $1-2,5 \mathrm{~cm}$ compr., pilosos. Bainhas foliares $0,8-2 \mathrm{~cm}$ compr., esparsa ou densamente pilosas, sem glândulas, persistentes, margens longo-ciliadas; lígula ca. $0,3 \mathrm{~mm}$ compr.; colo glabro. Lâminas $1-6 \times 0,2-1,5 \mathrm{~cm}$, ovallanceoladas, não congestas no colmo, esparsa a densamente pilosas ou glabrescentes, sem glândulas, base cordada, não amplexicaule, ápice agudo, margens escabras e longo-ciliadas na base com tricomas de base tuberculada. Panículas 3-8 $\times 2-5 \mathrm{~cm}$, ramificadas, terminais, abertas, exsertas, multifloras; ráquis flexuosa, pilosa, sem glândulas; ramos de primeira ordem pilosos, sem glândulas; pulvino densamente piloso; pedicelo piloso. Espiguetas $2-2,6 \times 0,7-0,9 \mathrm{~mm}$, elipsoides, verdes ou arroxeadas, esparsamente pilosas; gluma inferior $1,6-2,2 \times 0,8-0,9 \mathrm{~mm}, 1 / 2$ do comprimento da espigueta, monomórfica, 1- ou 3(5)-nervada, pilosa; gluma superior 1,5-2,1 × 0,9-1,1 mm, 7- ou 9-nervada, pilosa; lema inferior 1,5-2,1 ×0,8-1,1 mm, 7-nervado, piloso; pálea inferior ca. $1,5 \times 0,3 \mathrm{~mm}$, elíptica, hialina, glabra; flor inferior ausente; antécio superior 1,7-2,2 $\times$ 0,5-0,8 mm, elipsoide, não inflado na base, estramíneo, glabro com tricomas no ápice do lema. Cariopses ca. $1,5 \times 0,9 \mathrm{~mm}$, elipsoides, marrons; hilo punctiforme. 


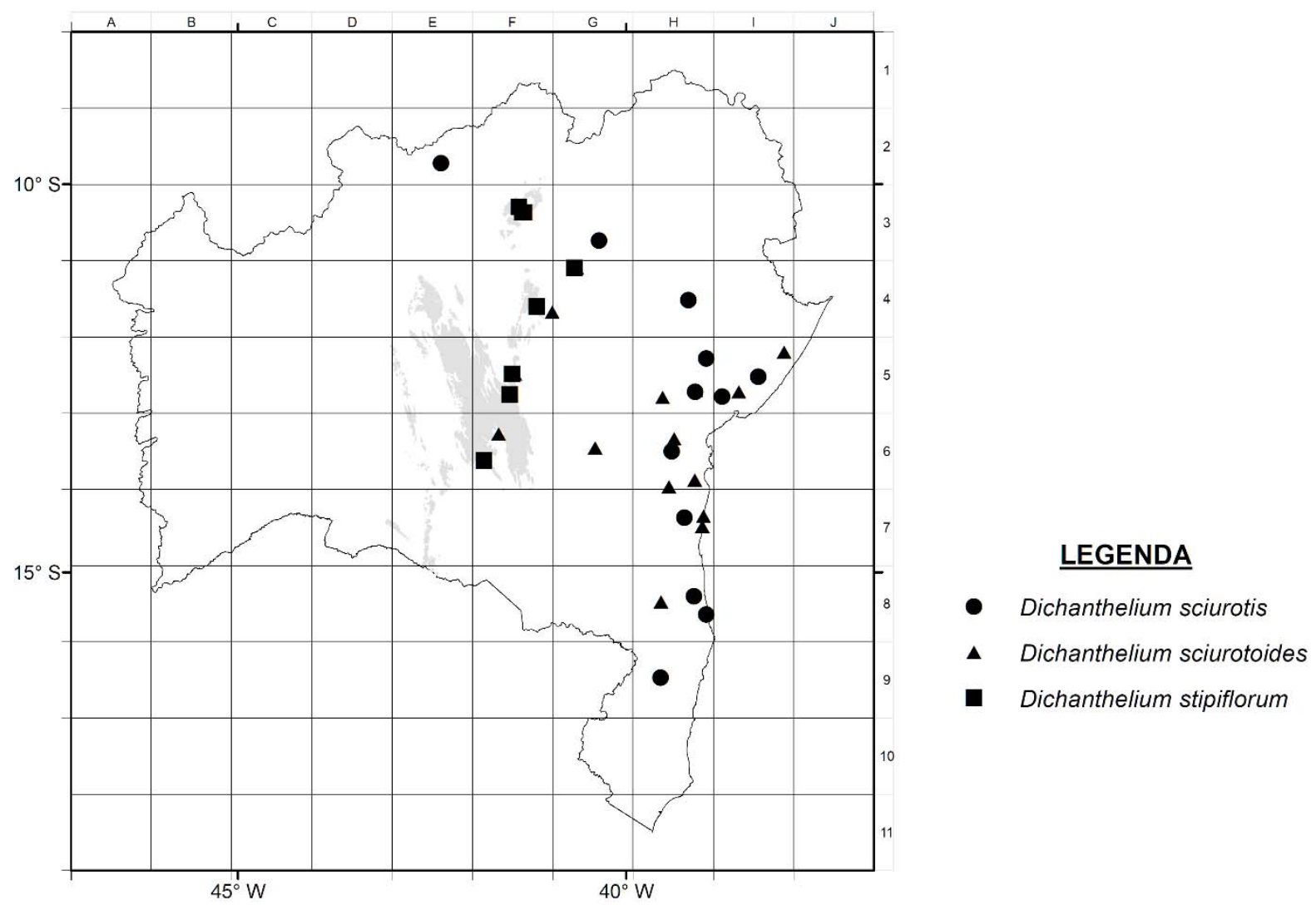

Figura 7. Mapa de distribuição de Dichanthelium sciurotis, D. sciurotoides e D. stipiflorum no estado da Bahia; em cinza, a região da Chapada Diamantina (acima de 900 m s.n.m.).

Endêmica da Bahia, entre 900 e $1.100 \mathrm{~m}$ de altitude (Renvoize 1982, 1984; Zuloaga et al. 1993). F3, F4, F5, F6 e G4: campos rupestres e caatingas, em solos pedregosos e arenosos.

Material examinado - Jacobina, $11^{\circ} 05^{\prime} \mathrm{S}, 40^{\circ} 40^{\prime} \mathrm{W}, 13$ abr. 1999, L.P. Queiroz et al. 5478 (HUEFS); Minas do Mimoso, $10^{\circ} 22^{\prime} \mathrm{S}, 41^{\circ} 20^{\prime} \mathrm{W}, 8$ mar. 1974, R.M. Harley 17004 (holótipo CEPEC, isótipo RB); Morro do Chapéu, $11^{\circ} 35^{\prime} \mathrm{S}, 41^{\circ} 12^{\prime} \mathrm{W}$, nov. 2018, A.O. Matos \& R.P. Oliveira 69 (HUEFS); Mucugê, $12^{\circ} 43^{\prime}$ 'S, 41 ${ }^{\circ} 30^{\prime} \mathrm{W}, 11$ nov. 2011, R.P. Oliveira et al. 2003 (HUEFS);

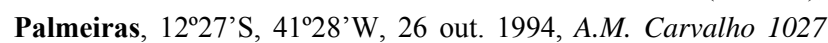

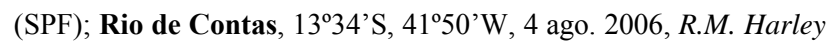
55527 (HUEFS); Sento Sé, $10^{\circ} 18^{\prime}$ 'S, $41^{\circ} 23^{\prime} \mathrm{W}, 1$ abr. 2002, K.R.B.

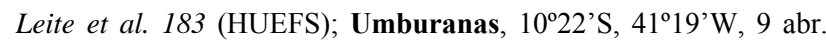
1999, L.P. Queiroz et al. 5210 (HUEFS).

É frequentemente confundida com Dichanthelium cumbucanum (veja nos comentários daquela espécie). Após a análise de um amplo número de espécimes de $D$. stipiflorum, concluímos que a indicação da espécie para o Rio de Janeiro, incluindo um espécime coletado na "Fazenda Mundo Novo. Botafogo" (Zehntner 263, RB; in sched.) e identificado como D. stipiflorum, deve ser um erro causado pela interpretação equivocada sobre o local de coleta, pouco legível na etiqueta. Assim, consideramos aqui apenas os registros coletados na Bahia como confiáveis para a espécie.

\section{Agradecimentos}

Agradecemos ao $\mathrm{CNPq}$ (Conselho Nacional de Desenvolvimento Científico e Tecnológico, processos 562349/2010-3 e 457427/2012-4); CAPES (Coordenação de Aperfeiçoamento de Pessoal de Nível Superior - 001) e FAPESB (Fundação de Amparo à Pesquisa do Estado da Bahia - PIE 009/2016) pelo suporte financeiro. Agradecemos também a Daniel Moura e aos colegas do LASIS (Laboratório de Sistemática de Insetos da UEFS) pela doação de fotos. Também agradecemos a CAPES pela bolsa de mestrado concedida a $\mathrm{AOM}$ e ao $\mathrm{CNPq}$ pela bolsa de pesquisa concedida a RPO (PQ1C).

\section{REFERÊNCIAS}

Aliscioni, S.S.; Giussani, L.M.; Zuloaga, F.O. \& Kellogg, E.A. 2003. A molecular phylogeny of Panicum (Poaceae: Paniceae): tests of monophyly and phylogenetic placement within the Panicoideae. American Journal of Botany 90: 796-821.

APG IV (The Angiosperm Phylogeny Group) 2016. An update of the Angiosperm Phylogeny Group classification for the orders and families of flowering plants: APG IV. Botanical Journal of the Linnean Society 181: 1-20. 
BFG (The Brazil Flora Group) 2015. Growing knowledge: an overview of Seed Plant diversity in Brazil. Rodriguésia 66(4): $1085-1113$

Brown, R.H. \& Smith, B.N. 1975. The genus Dichanthelium (Gramineae). Bulletin of the Torrey Botanical Club 102: 10-13.

Clayton, W.D. \& Renvoize, S.A. 1986. Genera Graminum: grasses of the world. Royal Botanic Gardens, Kew.

Delfini, C.; Matos, A.O. \& Zuloaga, F.O. 2020. Dichanthelium. In: Flora do Brasil 2020. Jardim Botânico do Rio de Janeiro. Disponível em: <http://floradobrasil.jbrj.gov.br/reflora/ floradobrasil/FB13157>. Acesso em: 17 ago. 2021.

Flora do Brasil 2020. Poaceae. In: Jardim Botânico do Rio de Janeiro. Disponível em: <http://floradobrasil.jbrj.gov.br/reflora/ floradobrasil/FB193>. Acesso em: 17 ago. 2021.

Giussani, L.M.; Cota-Sánchez, J.H.; Zuloaga, F.O. \& Kellogg, E. 2001. A molecular phylogeny of the grass subfamily Panicoideae (Poaceae) shows multiple origins of $\mathrm{C} 4$ photosynthesis. American Journal of Botany 88: 1993-2012.

Gould, F.W. 1974. Nomenclatural changes in the Poaceae. Brittonia 26: 59-60.

Hitchcock, A.S. \& Chase, A. 1910. The North American species of Panicum. Contributions from the United States National Herbarium 15: 1-396.

Kellogg, E.A. 2015. Flowering plants, Monocots, Poaceae. In: Kubitski, K. (ed.), The Families and Genera of Vascular Plants. Springer, Berlin, p. 1-416.

Lelong, M. 1984. New combinations for Panicum subgenus Panicum and subgenus Dichanthelium (Poaceae) of the southeastern United States. Brittonia 36: 262-273.

Longhi-Wagner, H.M. 2012. Poaceae: an overview with reference to Brazil. Rodriguésia 63: 89-100.

Longhi-Wagner, H.M.; Bittrich, V.; Wanderley, M.G.L. \& Shepherd, G.J. 2001. Poaceae. In: M.G.L. Wanderley, G.J. Shepherd \& A.M. Giulietti (coords.), Flora Fanerogâmica do Estado de São Paulo. Vol. 1. Fapesp \& Hucitec, São Paulo.

Maguire, B.; Wardack, J.K. \& al. 1957. The Botany of the Guayana Highland - Part II. Memoirs of the New York Botanical Garden 9: 235-392.

Matos, A.O.; Carneiro, J.S.; Oliveira I.L.C.; Leite, K.R.B; Silva, C. \& Oliveira, R.P. 2020. Macro and microcharacters reveal a new species of Dichanthelium (Poaceae, Panicoideae) endemic to sandy soils of the Chapada Diamantina, Bahia, northeastern Brazil. Phytotaxa 447: 149-162.

Morrone, O.; Denham, S.S.; Aliscioni, S.S. \& Zuloaga, F.O. 2008 Parodiophyllochloa, a new genus segregated from Panicum (Paniceae, Poaceae) based on morphological and molecular data. Systematic Botany 33: 66-76.
Morrone, O.; Aagesen, L.; Scataglini, M.A.; Salariato, D.L.; Denham, S.S.; Chemisquy, M.A.; Sede, S.M.; Giussani, L.M.; Kellogg, E.A. \& Zuloga, F.O. 2012. Phylogeny of the Paniceae (Poaceae: Panicoideae): integrating plastid DNA sequences and morphology into a new classification. Cladistics 28: 333-356.

Renvoize, S.A. 1982. A new genus and several new species of grasses from Bahia (Brazil). Kew Bulletin 37: 323-333.

Renvoize, S.A. 1984. The Grasses of Bahia. Royal Botanic Gardens, Kew.

Salariato, D.L.; Morrone, O. \& Zuloaga, F.O. 2011. A new species of Paniceae (Panicoideae, Poaceae) from Brazil. Systematic Botany 36: 53-58.

Soreng, R.J.; Peterson, P.M.; Romaschenko, K.; Davidse, G.; Teisher, J.K.; Clark, L.G.; Barbera, P.; Gillespie, L.J. \& Zuloaga, F.O. 2017. A world-wide phylogenetic classification of Poaceae (Gramineae) II: an update and comparison of two 2015 classifications. Journal of Systematics and Evolution 55: 259-290.

Swallen, J.R. 1949. New grasses from Honduras, Colombia, Venezuela, Ecuador, Bolivia and Brazil. In: C.V. Morton, S.F. Blake, J.R. Swallen, J. Swan, L.B. Smith, A.C. Smith \& A. Burkart (eds), Systematic Plant Studies. Contributions from the United States National Herbarium 29: 251-275.

Tutin, T. J. 1934. New species from British Guiana, Cambrigde University Expedition, 1933. In: A.B. Bendle (ed.), The Journal of Botany - British and Foreing. LXXIL, London, p. 333-341.

Zuloaga, F.O. 1987. Systematics of the New World species of Panicum (Poaceae: Paniceae). In: T.R. Soderstrom, K.W. Hilu, C.S. Campbell \& M.E. Barkworth (eds), Grass Systematics and Evolution. Smithsonian Institution Press, Washington, p. 287-306.

Zuloaga, F.O. \& Morrone, O. 1991a. New species of Panicum subgenus Dichanthelium (Poaceae: Paniceae) from South America. Annals of the Missouri Botanical Garden 78: 153163.

Zuloaga, F.O. \& Morrone, O. 1991b. Panicum sciurotoides, a new species of Panicum (Poaceae, Paniceae) from America. Novon 1: $1-5$.

Zuloaga, F.O.; Ellis, R.P. \& Morrone, O. 1993. A revision of Panicum subg. Dichanthelium sect. Dichanthelium (Poaceae: Panicoideae: Paniceae) in Mesoamerica, the West Indies, and South America. Annals of the Missouri Botanical Garden 80: 119-190.

Zuloaga, F.O.; Solomon, L. \& Scataglini, M.A. 2014. Phylogeny of sections Clavelligerae and Pectinatae of Panicum (Poaceae, Panicoideae, Paniceae): establishment of the new subtribe Dichantheliinae and the genus Adenochloa. Plant Systematics and Evolution 301: 1693-1711.

\section{LISTA DE EXsicatas}

Almeida, E.F. 22 (2); Amorim, A.M. 661 (12); Aona L.Y.S. 1370 (12), 4658 (8), 4765 (13); Araújo, J.S. 96 (2); Azevêdo-Gonçalves, C.F. 65 (2); Brito, J.C. 135 (2); Borba, E.L. 1905 (8); Carneiro, D.S. 42 (13); Carvalho, A.M. 1027 (13); Carvalho, D.N. 88, 309 (11); Conceição, A.A. 306 (13), 1076, 1089 (2); Cortes, A.L. 12 (3); Costa, G. 1462 (12), 2283 (2); Dorea, M.C. 36 (13), 50 (12), 51 , 59 (13), 67 (12); Ferreira, F.M. 2129 (11); Fraga, C.N. 2688 (8); França, F. 2786 (13); Fróes, R.L. 19950 (2); Ganev, W. 646 (6); Giullietti, A.M. 877 (2), 1448 , (6), 1453, 1454, (5), 1456 (6); Guedes, M.L.S. 761 (8), 7005, 7558, 7656, (11), 25472 (8); Harley, R.M. 15229 (4), 15930 (8), 16636 (12), 16869 (7), 17004 (13), 17383 (2), 24460 (1), 26320 (6), 26437 (1), 28679 (6), 55527 (13); Leite, K.R.B. 183 (13); Martinelli, G. 5230 (13) Martins, C.T.V.D. 421 (8); Mascarenhas, A.A.S. 142 (8); Matos, A.O. 69 (13), 70 (3), 74 (8), 75 (12), 76, 77, 78 (8), 73 (13); Mattos-Silva, L.A. 4344 (2); Melo, E. 3138 (13), 4955 (10), 5025, 5943 (13); Miranda, A.M. 6830 (11); Miranda, E.B. 306 (12); Mori, S.A. 12451 (1), 12475 (6); Mota, 
A.C. 73 (12), 191 (8), 192, 220 (12); Noblick, L.R. 2328, 2735 (11), 2870 (8); Oliveira, N.E. 288 (11); Oliveira, R.P. 623 (6), 1229 (12), 1260 , 1279 (13), 1298 (3), 1377 (12), 1810 (13), 1897 (8), 2003 (13), 2004 (12), 2038 (8), 2110,2137 (12), 2155 (8), 2175 (6); Paixão, J.L. 1374 (2); Pimenta, K.M. 125 (12), 130 (2), 456 (8); Pinto, G.C.P. 47-2 (12), 51-203, 51-330 (11), 92/85 (13), 42345 (12); Plowman, T. 10045 (2); Popovkin, A.V. 1779 (12); Queiroz, L.P. 5210, 5478 (13), 16282 (10); Sant'Ana, S.C. 719 (2); Santos, N.N.A. s.n. HUEFS 10055 (8); Silva, T.T. 281 (12); Snak. C. 1026 (11), 1047 (12); Souza, J.M. 105, 136 (2); Zuloaga, F.O. 2469 (2). 